\title{
Building an Honest Microfinance Organization: Embezzlement and the Optimality of Rigid Repayment Schedules and Joint Liability*
}

\author{
Doh-Shin Jeon ${ }^{\dagger}$ and Domenico Menicucci ${ }^{\ddagger}$
}

January 3, 2006

\begin{abstract}
We consider the agency problem of a staff member managing microfinancing programs, who can abuse his discretion to embezzle borrowers' repayments. The fact that most borrowers of microfinancing programs are illiterate and live in rural areas where transportation costs are very high make staff's embezzlement particularly relevant as is documented by Mknelly and Kevane (2002). We study the trade-off between the optimal rigid lending contract and the optimal discretionary one and find that a rigid contract is optimal when the audit cost is larger than gains from insurance. Our analysis explains rigid repayment schedules used by the Grameen bank as an optimal response to the bank staff's agency problem. Joint liability reduces borrowers' burden of respecting the rigid repayment schedules by providing them with partial insurance. However, the same insurance can be provided by borrowers themselves under individual liability through a side-contract.
\end{abstract}

JEL Code: O16, D82, G20

Key words: Microfinance, Contract, Embezzlement, Insurance, Joint Liability

${ }^{*}$ We thank seminar participants at Universidad Carlos III, Universitat Pompeu Fabra, Universite de Toulouse and ASSET 05 (Crete). We also thank Martin Besfamille, Bruno Biais, Vicente Cuñat, Xavier Freixas, Patrick Rey, Jean-Charles Rochet and Joel Shapiro for helpful comments. The first author gratefully acknowledges financial support from the Spanish Ministry of Science and Technology under BEC2003-00412 and Ramon y Cajal grant.

†Universitat Pompeu Fabra and CREA, Barcelona, Spain. doh-shin.jeon@upf.edu

${ }^{\ddagger}$ Università degli Studi di Firenze, Italy. domenico.menicucci@dmd.unifi.it 


\section{Introduction}

The remarkable success of microfinance programs in making loans to (and recovering them from) the poor has received world-wide attention and generated a global microfinance movement which has been growing rapidly: according to the report from the Microcredit Summit Campaign, by the end of 2002, 67.6 million clients were served worldwide by over 2,500 microfinance institutions (Armendáriz de Aghion and Morduch, 2005, p.3). The original ideas of microfinance are due to Muhammad Yunus, the founder of the Grameen bank, who started making small loans to groups of poor people in rural area in Bangladesh in the 1970s. Today the Grameen bank is a large financial organization: it disbursed $\$$ 482.90 million during the 12 months from May 2004 to April 2005 to about 4.5 million borrowers and its loan recovery rate is about 99 percent. $^{1}$

Most of the existing literature on microfinance has centered on how group lending, in particular joint liability, affects adverse selection (Ghatak, 1999, 2000, Van Tassel, 1999, Armendáriz de Aghion and Gollier 2000, Laffont and N'Guessan 2000, Laffont, 2003), moral hazard in terms of loan repayment (Besley and Coate, 1995, Armendáriz de Aghion 1999, Rai and Sjöström, 2004) and moral hazard before return realization such as work incentive (Stiglitz 1990, Varian 1990, Conning 1999, Che 2002, Laffont and Rey, 2003). ${ }^{2}$ Despite the variety of the issues that the papers examine, all of them, except Conning (1999) who studies the trade-off between outreach and financial leverage, consider only borrowers' incentives and do not study the incentive issues of the staff managing the loans. Furthermore, most papers consider state-contingent repayments without investigating a staff member's incentive to reveal his ${ }^{3}$ information about the realized state of nature to the bank. However, corruption and embezzlement are rampant in most organizations in underdeveloped countries ${ }^{4}$ and the Grameen bank is a large organization involving several layers of hierarchy. ${ }^{5}$ Hence, understanding the success of the Grameen bank requires also

\footnotetext{
${ }^{1}$ http://www.grameen-info.org/bank/GBGlance.htm.

${ }^{2}$ See Ghatak and Guinnane (1999) and Morduch (1999) for surveys. The book written by Armendáriz de Aghion and Morduch (2005) also reviews some recent papers that focus on issues different from joint liability such as dynamic incentives, competition, the use of collateral, etc.

${ }^{3}$ We use she for the lender and he for a staff member (or a supervisor) or a borrower.

${ }^{4}$ For instance, Angolan officials are accused of embezzling 10 percent of the country's GDP during the last five years. (Fantaye, 2004, p.173).

${ }^{5}$ At the time of April 2005, the Grameen bank has 4.48 million borrowers and 1,456 branches. It works in 51,687 villages and the number of its staff is 13,492. (http://www.grameeninfo.org/bank/GBGlance.htm). The hierarchy is composed of head office, zonal office, area office, branch office, center, group, member (Bornstein, 1997 p. 176).
} 
understanding how its lending contracts successfully solve (or mitigate) agency problems inherent in a hierarchy. Our paper addresses the question of how an organization that manages so much money in a corrupt society can remain honest. ${ }^{6}$

Since most borrowers of microfinancing programs in poor countries are illiterate ${ }^{7}$ and means of transportation are primitive, they get informed about the conditions of the loan exclusively through the bank staff member who visits their villages to collect repayments and to monitor their behavior (regarding how the loan is invested and whether they undertake adequate effort). This creates significant scope for the member's misconduct, ${ }^{8}$ and for embezzlement in particular, as documented by Bornstein (1996) ${ }^{9}$ and Mknelly and Kevane (2002). For instance, according to Mknelly and Kevane (2002), room for embezzlement arises because illiterate borrowers cannot maintain their account books. ${ }^{10}$ Furthermore, contract enforcement problems related to limited liability exist not only at the level of borrowers but also at the level of staff.

In this paper, we study the optimal lending contract and the optimal supervisory contract when a staff member can embezzle repayments by misrepresenting the realized state when a loan contract specifies state-contingent repayments. To focus on the staff's incentive problem, we assume away any adverse selection or moral hazard at the level of borrower(s). Therefore, our approach is complementary to the approach taken by the existing literature which focuses on borrowers' incentive problems and allows us to explain two main features of the lending contracts used by the Grameen bank, rigid repayment schedules and joint liability, as optimal responses to bank staff's agency problem. Contrary to the findings of the most papers on group lending that show the optimality of stage-contingent repayments, the lending contracts of the Grameen bank specify a rigid repayment schedule which does not depend on the realization of the state; almost immediately after receiving a loan, a borrower has to start to pay back his weekly repayment

\footnotetext{
${ }^{6}$ An employee of the Grameen bank says "Every other organization in Bangladesh is full of corruption. Here, you can be an honest person and it's possible to remain so." (Bornstein 1997, p. 167)

${ }^{7}$ According to Yunus $(1998$, p. 24), "We have worked with ... women who cannot read and write....."

${ }^{8}$ Bazoberry (2001, p.13) describes six unauthorized activities that staff members of some microfinance organizations in Bolivia engaged in such as creation of "ghost" loans to hide the fact that goals are not met and utilization of inactive saving accounts to pay for outstanding debts etc.

${ }^{9}$ Bornstein writes about the embezzlement in the early period of the Grameen bank (pp. 169-174).

${ }^{10}$ For this reason, staff often take the responsibility of maintaining account books. However, when the authors investigated a staff member's accounting book, they found "... the account book had no entry for the group fund. There was no carryover from one cycle to the next, and no entries in the log of deposits and withdrawals"(p. 2028).
} 
which is fixed for the whole period of the lending contract. ${ }^{11}$

We consider a simple model of hierarchy: there are a lender, a supervisor (i.e. a bank staff member) and borrower(s). The supervisor has the task to check the success or failure of the project(s) undertaken by the borrower(s) and to collect the repayment(s). The lender can use either a rigid lending contract in which the borrower makes the same payment regardless of the realization of the state, or any discretionary contract in which the repayment depends on the realization of the state. If the lender uses the latter, the supervisor has some discretion in that when a project succeeded, he can report that the project failed and embezzle the difference between the payment upon success and the payment upon failure. The lender can use incentive pays and/or audit to induce the supervisor to behave well. We assume that, when a cheating supervisor is discovered, the lender can recover the original payment made by the borrower and punish the supervisor by not paying him his salary but cannot impose any further fine because of limited liability. ${ }^{12}$

As is usual in the literature on microfinance ${ }^{13}$, the lender is assumed to maximize the borrower(s)' payoff subject to the break-even constraint. We assume that a borrower's marginal cost of paying back one unit of money is higher when his project fails than when it succeeds. Therefore, in the benchmark of a honest supervisor, it is optimal for the bank to provide insurance to the borrower by recovering all financing cost through a repayment upon success.

In section 3, we consider the case of a single borrower and study the optimal lending contract and the optimal supervisory contract. Individual lending programs are often used by microfinance programs ${ }^{14}$ and our single borrower case clarifies the trade-off between the optimal rigid lending contract and the optimal discretionary one. We start by characterizing the optimal supervisory contract for a given discretionary lending contract. It turns out that it is optimal to use either incentive pays only or audit only. We prove that the optimal lending contract is either a rigid contract or a discretionary contract. In the former case, the supervisor has no discretion and neither bonus nor audit is necessary, while using only audit is optimal in the latter case. The optimal contract is rigid when the audit cost is larger than the borrower's burden of respecting the fixed repayment schedule

\footnotetext{
${ }^{11}$ Yunus (1998, p.110) describes the repayment mechanism of the Grameen bank as: (i) one year loan (ii) equal weekly installments (iii) repayment starts one week after the loan etc.

${ }^{12}$ If a large fine can be imposed, the lender can eliminate the supervisor's embezzlement incentive at almost zero cost.

${ }^{13}$ For instances, see Armendáriz de Aghion (1999), Ghatak (1999, 2000), Rai and Sjöström (2004) etc.

${ }^{14}$ According to the Microbanking Bulletin (2002), 73 over 147 best microfinance programs surveyed make loans to individuals.
} 
when his project fails. In other words, the optimal contract is rigid when the audit cost is larger than the gain from providing insurance for the borrower.

In section 4, we consider the case of two borrowers and derive the optimal lending contract and the optimal supervisory contract both with and without joint liability. Note first that in our model joint liability does not affect the net present value (NPV) of the project when the supervisor is honest and hence there is no particular reason to adopt it in the absence of the supervisor's agency problem. We find that joint liability strictly increases the NPV both under the optimal rigid contract and under the optimal discretionary contract. Joint liability can thus be regarded as an optimal response to the embezzlement problem. For instance, if the auditing cost is sufficiently high that a rigid contract is optimal, then joint liability reduces the borrowers' burden of respecting a rigid repayment schedule by providing them with partial insurance: although the total repayment does not depend on the realized state in a rigid contract, some partial insurance can be provided in the state in which only one borrower's project succeeds by increasing his repayment and reducing the other's repayment. However, we show that if the borrowers can sign a side-contract for mutual insurance, the outcome of the optimal rigid contract under joint liability can be achieved also under individual liability.

Agency problems in hierarchies have been a major theme of research in economics. For instances, Williamson (1967) and Calvo and Wellisz (1978) study when and how loss of control in a hierarchy limits the size of firm. Our paper is more closely related to the literature on collusion between a supervisor and an agent in the mechanism design theory (Tirole 1986, Laffont and Tirole 1991, Kofman and Lawarrée 1993 and Faure-Grimaud, Laffont and Martimort 2003). In the literature, they derive the optimal collusion-proof contract when the supervisor can manipulate the information he reports to the principal about the agent's type in exchange for a bribe. We do not consider the collusion but focus on the supervisor's incentive to manipulate the information he reports to the lender regarding the realized return of the project(s). ${ }^{15}$

Although our paper is related to the literature on costly state verification (Townsend 1979, Diamond 1984, Gale and Hellwig 1985) in that the lender can conduct audit to verify the realized return, to our knowledge it is the first paper that considers a hierarchy in the framework of costly state verification and tackles the supervisor's incentive to embezzle borrowers' repayments. Another difference is that while the previous literature assumes that the borrower cannot repay the loan for some states and derive the optimality of a state-contingent repayment contract such as a debt contract, we assume that the borrower

\footnotetext{
${ }^{15}$ Note that in section 4.4 , we consider side-contracting between borrowers.
} 
is able to repay the loan even when the project fails, ${ }^{16}$ which is consistent with the $99 \%$ of repayment rate in the Grameen bank, and focus on the trade-off between a rigid repayment schedule and a state-contingent one.

In the microfinance literature, only a few papers (Conning, 1999 and Aubert, Janvry and Sadoulet 2005) consider a hierarchy. ${ }^{17}$ For instance, Conning (1999) studies both a borrower's incentive to divert the fund and a staff member's incentive to monitor the former's misbehavior. ${ }^{18}$ However, he does not study the staff's incentive to embezzle repayments since he assumes that the realized return is common knowledge as most papers on microfinance do. Furthermore, he considers only one instrument (i.e. incentive pay) to affect the staff member's incentive while we consider two instruments: incentive pay and audit. In Armendáriz de Aghion (1999), Armendáriz de Aghion and Gollier (2000), Rai and Sjöström (2004), the realized return of a borrower's project is his private information. However, none of them consider a hierarchy. For instance, Rai and Sjöström (2004) study the efficient lending contracts that induce the borrowers to truthfully report their information about the realized returns and show that, for instance, in the absence of the collusion between the borrowers, the outcome of the first-best contract (which is a debt contract and hence state-dependent) can be implemented through a cross-reporting mechanism when they share information about the returns. ${ }^{19}$ By contrast, we consider the efficient lending contracts that induce the supervisor to truthfully report his information about the realized returns and derive the condition under which a state-independent contract is optimal. Our results suggest that increasing staff's discretion to enable them to use more local information for borrowers' benefit, as is suggested by cross-reporting, can involve the cost of increasing the scope for their misconduct and thereby can backfire.

Section 2 presents the model for the case of a single borrower and section 3 analyzes this case. Section 4 analyzes the case of two borrowers. Section 5 discusses our results and section 6 concludes. All the proofs that are not presented in the main text are gathered in Appendix.

\footnotetext{
${ }^{16}$ This assumption is justified given the small size of the loans in microfinance programs.

${ }^{17}$ See also chapter 10 of Armendáriz de Aghion and Morduch (2005).

${ }^{18}$ Aubert, Janvry and Sadoulet (2005) study the conflict between a not-for profit microfinance organization and its staff member in terms of the incentive to reach poor borrowers instead of less poor. However, they also assume the state-contingent lending contract.

${ }^{19}$ Laffont and Rey (2003) also show the optimality of cross-reporting in the absence of collusion in terms of inducing effort.
} 


\section{Basic model}

We consider a hierarchy composed of a lender, a supervisor and a borrower. The borrower borrows one unit of money from the lender and invests it in a project. The lender is risk neutral and designs the contracts. She is assumed to maximize the borrower's payoff as long as her break-even constraint is satisfied. To break even, she needs to recover an amount $\rho(>1)$, the opportunity cost of the loan, plus the wage bill paid to the supervisor and the cost of audit.

Let $Y$ denote the revenue generated by the borrower's investment: with probability $p \in(0,1)$, the project succeeds and $Y=Y_{S}>0$; with probability $1-p$, it fails and $Y=Y_{F}$ $(=0)$. A lending contract, represented by $\left\{r_{S}, r_{F}\right\}$, specifies a repayment contingent on the state: the borrower should pay $r_{S}$ when $Y=Y_{S}$ and $r_{F}$ when $Y=Y_{F}$. In order to focus on the moral hazard of the supervisor, we assume that the borrower always pays $r_{i}$ back for any state $i=S, F$. In reality, dynamic incentives not modeled in this paper can induce a borrower to pay back since he highly values the opportunity to borrow larger and larger amounts of money in the future. ${ }^{20}$ Without loss of generality, we require $r_{i}$ to be non-negative, $i=S, F .^{21}$

The lender does not ask for any collateral, as it is the case with the Grameen bank. In the case of failure, in order to generate cash $r_{F}$, the borrower should reduce his consumption $^{22}$ (or sell his asset, or borrow money from local money lenders charging usurious interest rates $\left.^{23}\right)$. This is costly in the following sense: generating $r$ units of money costs $\psi(r)$ to the borrower, with $\psi(0)=0, \psi^{\prime}(r)>1$ and $\psi^{\prime \prime}(r) \geq 0$ for any $r>0$; hence, $\psi(r)>r$ for $r>0$. Let $U\left(Y_{i}, r_{i}\right)$ denote the borrower's utility in state $i$. We assume:

$$
\begin{array}{ll}
U\left(Y_{i}, r_{i}\right)=Y_{i}-r_{i}, & \text { if } Y_{i}-r_{i} \geq 0 \\
U\left(Y_{i}, r_{i}\right)=-\psi\left(r_{i}-Y_{i}\right) & \text { if } Y_{i}-r_{i}<0
\end{array}
$$

Thus, given a state $i=S, F$, the borrower's marginal utility of one unit of money is 1

\footnotetext{
${ }^{20}$ This is a main feature of the Grameen lending. See chapter 5.2 of Armendáriz de Aghion and Morduch (2005) for more details on the dynamic incentives.

${ }^{21}$ We can obtain our results even though $r_{i}$ can be negative, but considering this case makes the proofs longer without adding economic insight. In short, even though the constraint $r_{F} \geq 0$ binds in our analysis, one cannot strictly improve the borrowers' payoff by allowing $r_{F}<0$, as we explain in remark 1 in section 3 .

${ }^{22}$ For instance, Bornstein (1997, p.149) documents the story of a woman who purchased a cow with the money borrowed from the Grameen bank. Since the cow stopped lactating midway through the year, she had to cut down on her family's eating to pay back the weekly installments.

${ }^{23}$ Jain and Mansuri (2003) provide evidence of microfinance members' borrowing money from local lenders.
} 
if $Y_{i}-r_{i} \geq 0$ while it is larger than 1 if $Y_{i}-r_{i}<0$. This decreasing marginal utility of money makes the borrower risk averse. We say that the borrower is fully insured if $r_{F}=0$ and $r_{S} \leq Y_{S}$; then, he makes a payment to the lender only in state $S$ and the marginal utility from additional money is equal to one regardless of the realized state. When $r_{S} \leq Y_{S}$ and $r_{F} \geq 0$, his expected payoff upon accepting the contract is given by:

$$
p\left(Y_{S}-r_{S}\right)-(1-p) \psi\left(r_{F}\right)
$$

The supervisor has the task to check and report the state (whether $i=S$ or $F$ ) and to collect the borrower's repayment $r_{S}$ or $r_{F}$. A supervisory contract specifies a wage for the supervisor contingent on the state he reports: the wage is $w_{S}$ if he reports $i=S$ and $w_{F}$ if he reports $i=F$. Since the means of transportation are primitive, the supervisor must visit the borrower to get the repayment and we assume that as long as he visits the borrower, he can costlessly verify the state. Furthermore, we assume that the supervisor is protected by limited liability and therefore his wage cannot be lower than a certain $\underline{w} \geq 0$ (i.e. $\min \left\{w_{S}, w_{F}\right\} \geq \underline{w}$ ), which is the supervisor's reservation utility or the minimum wage. Limited liability can arise for instance from the supervisor's having freedom to quit. $^{24}$

We focus on the moral hazard of the supervisor, who can misrepresent the state to the lender. For instance, when $\Delta \equiv r_{S}-r_{F}>0$, by reporting $i=F$ when $i=S$ the supervisor can embezzle $\Delta$. Since embezzlement requires visiting the borrower, we assume that the cost of visiting the borrower is zero for simplicity. The lender can audit the actual payment made by the borrower at the cost of $k(>0)$. When cheating is discovered, the lender can recover $\Delta$ and refuse to pay any wage to the supervisor. However, since the supervisor is protected by limited liability, we assume that the lender cannot impose any further fine on him. If she can impose a large fine, it is easy to show that she can eliminate the moral hazard at almost zero cost: for instance, by conducting an audit with a small probability $\varepsilon(>0)$ and imposing a large fine if embezzlement is discovered, she can solve the moral hazard at the cost of $\varepsilon k$. Hence, we focus on the case of zero fine. A supervisory contract is represented by $\left\{q_{i}, w_{i}\right\}$ with $i=S, F$, where $q_{i}$ represents the probability of audit when the supervisor reports $i$. For simplicity, the supervisor is assumed to be risk-neutral.

A grand-contract $\left\{r_{i}, w_{i}, q_{i}\right\}_{i=S, F}$ is composed of a lending contract $\left\{r_{S}, r_{F}\right\}$ and a supervisory contract $\left\{w_{S}, w_{F}, q_{S}, q_{F}\right\}$. We assume that the lender makes a take-it-orleave-it offer to both the supervisor and the borrower. When the supervisor is honest, $\left\{r_{S}=(\rho+\underline{w}) / p, r_{F}=q_{F}=q_{S}=0, w_{S}=w_{F}=\underline{w}\right\}$ is the optimal grand-contract pro-

\footnotetext{
${ }^{24}$ For instance, Conning (1999) assumes limited liability with $\underline{w}=0$.
} 
vided that $p Y_{S}>\rho+\underline{w}$. In particular, it provides the borrower with full insurance since no repayment is required when the project fails (i.e. $r_{F}=0$ ).

For expositional facility, we define two kinds of lending contracts, rigid and discretionary, and two kinds of supervisory contracts, with a carrot and with a stick.

Definition: A lending contract is said to be rigid if $\Delta=0$. A lending contract is said to be discretionary if $\Delta \neq 0$. Given a total cost $C$ of financing the project, a contract with $r_{S}=C / p$ and $r_{F}=0$ is called a contract with maximum discretion.

Definition: A supervisory contract with $\left(w_{S}-w_{F}\right)\left(r_{S}-r_{F}\right)>0$ and $q_{F}=q_{S}=0$ is called a supervisory contract with a carrot. A supervisory contract with $w_{S}=w_{F}$ and $q_{F}>0$ or $q_{S}>0$ is called a supervisory contract with a stick.

In a rigid lending contract, the supervisor has no discretion since the borrower's payment does not depend on the state of nature. By contrast, the supervisor has some discretion when $\Delta \neq 0$; the amount of discretion is given by $|\Delta|$. We show later on (in lemma 1) that we need to consider only lending contracts with $\Delta \geq 0$. Given a total cost $C$ of financing the project, a contract with $r_{S}=C / p$ and $r_{F}=0$ gives the maximum discretion to the supervisor while providing full insurance for the borrower. When $\Delta>0$, there are two different ways to induce the supervisor not to embezzle $\Delta$. If the lender does not use audit $\left(q_{F}=q_{S}=0\right)$, she must award an incentive pay: $w_{S}$ must be (sufficiently) larger than $w_{F}$. If no incentive pay is used, audit must be used frequently enough. In the former case the lender uses a carrot (i.e. the incentive pay), while, in the latter case, she uses a stick in that if the embezzlement is detected, the supervisor loses his wage and the stolen repayment is recovered by the lender.

In section 3 in which we consider the case of one borrower, we first study the optimal supervisory contract given $\left\{r_{S}, r_{F}\right\}$ and then derive the optimal lending contract by comparing the optimal rigid contract with the optimal discretionary contract. Since we are mainly interested in this comparative static, we make the following assumption, in which $\Delta^{\max }$ denotes the largest solution to the equation

$$
\rho+\underline{w}+(1-p) \frac{\Delta}{\Delta+\underline{w}} k=p \Delta
$$

A1: $Y_{S}$ is large enough such that the net present value (NPV) of the project (i.e., the borrower's expected utility) is positive at the equilibrium: $p Y_{S}>\rho+\underline{w}+(1-p) \min \{\psi(\rho+$ $\left.\underline{w})-\rho-\underline{w}, k \frac{\Delta^{\max }}{\Delta^{\max }+\underline{w}}\right\}$. 
For instance, when the supervisor is honest, the project's NPV is positive if and only if $p Y_{S}-\rho-\underline{w}>0$. A1 means that $p Y_{S}$ is sufficiently larger than $\rho+\underline{w}$ such that the NPV is positive even in the presence of the cost generated by the supervisor's moral hazard. This allows us to neglect the borrower's participation constraint.

\section{Single borrower case}

In this section, we derive the optimal grand-contract in the case of a single borrower. From the revelation principle, there is no loss of generality in restricting our attention to direct revelation mechanisms ${ }^{25}$ that induce the supervisor to report the true state to the lender. Therefore, a grand-contract should satisfy the following incentive constraints to induce the supervisor to report truthfully the state of the world:

$$
\begin{array}{ll}
\left(I C_{S F}\right) & w_{S} \geq\left(1-q_{F}\right)\left(r_{S}-r_{F}+w_{F}\right) \\
\left(I C_{F S}\right) & w_{F} \geq\left(1-q_{S}\right)\left(r_{F}-r_{S}+w_{S}\right) .
\end{array}
$$

A grand-contract must also satisfy the lender's break-even constraint given by:

$$
(B E) \quad p r_{S}+(1-p) r_{F} \geq \rho+p w_{S}+(1-p) w_{F}+\left[p q_{S}+(1-p) q_{F}\right] k,
$$

where the right hand side represents the total financing cost that the lender needs to recover. The lender's optimization problem, denoted by $\left(L^{S}\right),{ }^{26}$ is defined as follows:

$$
\begin{gathered}
\max _{\left\{r_{i}, w_{i}, q_{i}\right\}_{i=S, F}} p\left(Y_{S}-r_{S}\right)-(1-p) \psi\left(r_{F}\right) \\
\text { subject to } \\
(B E), \quad\left(I C_{S F}\right), \quad\left(I C_{F S}\right), \quad r_{i} \geq 0, \quad w_{i} \geq \underline{w} \quad \text { for } i=S, F .
\end{gathered}
$$

The following useful lemma (i) proves an important property of the borrower's utility function which is repeatedly used in our paper and (ii) shows that we can focus on contracts such that $r_{S} \geq r_{F}$.

Lemma 1 When there is a single borrower,

(i) Suppose that the lending contracts $\left\{r_{S}, r_{F}\right\}$ and $\left\{r_{S}^{\prime}, r_{F}^{\prime}\right\}$ have the same expected payment and $r_{F}>r_{F}^{\prime} \geq 0$. Then the borrower prefers $\left\{r_{S}^{\prime}, r_{F}^{\prime}\right\}$ to $\left\{r_{S}, r_{F}\right\}$.

(ii) The optimal lending contract is such that $\Delta \geq 0$.

\footnotetext{
${ }^{25}$ According to Laffont and Martimort (2002, section 3.6), the revelation principle holds when the principal can commit to audit mechanisms as in our case.

${ }^{26}$ The large $L$ means the "lender" and the superscript $S$ means a "single" borrower.
} 
Proof. (i) If $p r_{S}^{\prime}+(1-p) r_{F}^{\prime}=p r_{S}+(1-p) r_{F} \equiv r^{e}$, then $p\left(Y_{S}-r_{S}^{\prime}\right)-(1-p) \psi\left(r_{F}^{\prime}\right)=$ $p Y_{S}-r^{e}+(1-p)\left(r_{F}^{\prime}-\psi\left(r_{F}^{\prime}\right)\right)$. This function of $r_{F}^{\prime}$ is equal to (1) at $r_{F}^{\prime}=r_{F}$ and is decreasing with respect to $r_{F}^{\prime}$.

(ii) Suppose that a grand contract $G=\left\{r_{S}, r_{F}, w_{S}, w_{F}, q_{S}, q_{F}\right\}$ satisfies (4) and is such that $r_{S}<r_{F}$. We now find $G^{\prime}=\left\{r_{S}^{\prime}, r_{F}^{\prime}, w_{S}^{\prime}, w_{F}^{\prime}, q_{S}^{\prime}, q_{F}^{\prime}\right\}$ which satisfies (4) and increases the borrower's payoff with respect to $G$. Precisely, let $r_{S}^{\prime}=r_{F}^{\prime}=p r_{S}+(1-p) r_{F}$ and $w_{S}^{\prime}=w_{F}^{\prime}=\underline{w}, q_{S}^{\prime}=q_{F}^{\prime}=0$. Then, (a) $G^{\prime}$ satisfies $\left(I C_{S F}\right)$ and $\left(I C_{F S}\right)$; (b) the financing cost with $G^{\prime}$ is equal to $\rho+\underline{w}$, the minimum feasible cost: therefore, it cannot be larger than the cost under $G$; (c) the borrower's expected payment (the left hand side of $(B E)$ ) with $G^{\prime}$ is the same as with $G$. Hence, $G^{\prime}$ satisfies (4) and the borrower's expected utility is higher with $G^{\prime}$ by lemma $1(\mathrm{i})$ since $r_{F}<r_{F}^{\prime}$.

The intuition for lemma $1(\mathrm{i})$ is that although the expected payment is the same, the borrower pays less in state $F$ with $\left\{r_{S}^{\prime}, r_{F}^{\prime}\right\}$ than with $\left\{r_{S}, r_{F}\right\}$; thus, with the former contract he bears a smaller cost of reducing consumption when his project fails. Lemma 1(ii) relies on lemma 1 (i) to show that we can restrict our attention to lending contracts with $\Delta \geq 0$. Precisely, it proves that if $r_{S}<r_{F}$, then increasing the payment in state $S$ and decreasing the payment in state $F$ without modifying the expected payment has the effect of relaxing the incentive constraints (because the room for embezzlement is reduced) and increasing the borrower's expected utility.

When $\Delta \geq 0$ holds, the supervisor has no incentive to misrepresent the state from $F$ to $S$ in the absence of any incentive pay or audit. Accordingly, we consider the relaxed problem in which $\left(I C_{F S}\right)$ is neglected; but we prove that $\left(I C_{F S}\right)$ is satisfied in the solution of this relaxed problem. We observe that in the relaxed problem it is optimal to set $q_{S}=0$ in order to minimize the financing cost. For notational simplicity, in the rest of this section we let $q \equiv q_{F}$.

We now solve $\left(L^{S}\right)$ in two steps. First, given a lending contract $\left\{r_{S}, r_{F}\right\}$, we find the optimal supervisory contract $\left\{w_{S}, w_{F}, q\right\}$ that minimizes the cost of financing the project, $\rho+p w_{S}+(1-p) w_{F}+(1-p) q k$, subject to $\left(I C_{S F}\right), w_{S} \geq \underline{w}$ and $w_{F} \geq \underline{w}$; it is important to notice that $\left\{r_{S}, r_{F}\right\}$ affects $\left(I C_{S F}\right)$ only through $\Delta \geq 0$. Second, we maximize the borrower's expected utility with respect to $\left(r_{S}, r_{F}\right)$ subject to $(B E) .{ }^{27}$

\footnotetext{
${ }^{27}$ This methodology is similar to the one followed in a standard model of moral hazard in which (i) given an effort level to implement, one finds the incentive scheme which minimizes the cost of implementing that effort and (ii) one finds the optimal effort.
} 


\subsection{The optimal supervisory contract given $\Delta$}

In this subsection we find the optimal supervisory contract given a lending contract (i.e. given $\Delta \geq 0$ ) by solving the following problem, denoted by $\left(S^{S}\right):^{28}$

$$
\min _{w_{S}, w_{F}, q} \rho+p w_{S}+(1-p) w_{F}+(1-p) q k
$$

subject to

$$
\left(I C_{S F}\right), \quad w_{S} \geq \underline{w} \quad \text { and } \quad w_{F} \geq \underline{w} .
$$

A first step is given by a simple lemma:

Lemma 2 When there is a single borrower, the solution to $\left(S^{S}\right)$ for a given $\Delta \geq 0$ is such that

(i) $w_{F}=\underline{w}$;

(ii) if $\Delta=0$, then $w_{S}=\underline{w}$ and $q=0$;

(iii) if $\Delta>0$, then $\left(I C_{S F}\right)$ binds and $q \leq \bar{q}(\Delta) \equiv \Delta /(\Delta+\underline{w})$;

(iv) $\left(I C_{F S}\right)$ is satisfied.

Proof. (i) Reducing $w_{F}$ improves the objective function and relaxes $\left(I C_{S F}\right)$. Therefore $w_{F}$ is equal to $\underline{w}$, the smallest feasible value.

(ii) Since the supervisor has no discretion $(\Delta=0)$, there is no need to use incentive pay or audit.

(iii) Suppose that $\Delta>0$ and $\left(I C_{S F}\right)$ is slack. Then it is optimal to set $w_{S}=\underline{w}$ and $q=0$, but a contradiction arises because $\left(I C_{S F}\right)$ is violated, given $\Delta>0$. If $q>\Delta /(\Delta+\underline{w})$, then the right hand side of $\left(I C_{S F}\right)$ is smaller than $\underline{w}$ and $\left(I C_{S F}\right)$ is slack.

(iv) If $\left(I C_{S F}\right)$ is slack, then $w_{S}=\underline{w}$ and $\left(I C_{F S}\right)$ reduces to $\underline{w} \geq-\Delta+\underline{w}$. If $\left(I C_{S F}\right)$ binds, then $\left(I C_{F S}\right)$ is $\underline{w} \geq-\Delta+(1-q)(\Delta+\underline{w})$, equivalent to $q \underline{w} \geq-q \Delta$.

In what follows we consider the case of $\Delta>0$. Since $\left(I C_{S F}\right)$ binds, we find $w_{S}=$ $(1-q)(\Delta+\underline{w})$. The objective function after replacing $w_{S}$ with $(1-q)(\Delta+\underline{w})$ in $\left(S^{S}\right)$ is

$$
\rho+p(1-q)(\Delta+\underline{w})+(1-p) \underline{w}+(1-p) q k
$$

We need to minimize this function with respect to $q$, for $q \in[0, \bar{q}(\Delta)]$. Since the function is linear in $q$, the optimum is easily found as follows. Let $\bar{\Delta} \equiv(1-p) k / p-\underline{w}$. Then, $q=0$ is optimal if $\Delta \leq \bar{\Delta}$ while $q=\bar{q}(\Delta)$ is optimal if $\Delta>\bar{\Delta}$. The following proposition summarizes these results by characterizing the optimal supervisory contract as a function of $\Delta \geq 0$ and gives the associated financing cost.

\footnotetext{
${ }^{28}$ The large $S$ means a "supervisory contract".
} 
Proposition 1 When there is a single borrower, given a lending contract with $\Delta \geq 0$, the optimal supervisory contract is characterized as follows. There exists $\bar{\Delta} \equiv(1-p) k / p-\underline{w}$ such that

(i) (Carrot regime) For $0 \leq \Delta \leq \max \{0, \bar{\Delta}\}, q=0$ and $w_{S}=\underline{w}+\Delta, w_{F}=\underline{w}$; the financing cost is $\rho+p \Delta+\underline{w}$;

(ii) (Stick regime) For $\Delta \geq \max \{0, \bar{\Delta}\}, q=\bar{q}(\Delta)$ and $w_{S}=w_{F}=\underline{w}$; the financing cost is $\rho+\underline{w}+(1-p) \bar{q}(\Delta) k$.

We now provide an intuitive explanation of the optimal supervisory contract by considering the case in which $\bar{\Delta}>0$. Note first that because the total financing cost in the objective function and $\left(I C_{S F}\right)$ are linear with respect to $q$, the optimal $q$ is either zero (i.e. no audit) or $\bar{q}(\Delta)$, which is the minimal $q$ that satisfies $\left(I C_{S F}\right)$ at the minimum wage $w_{S}=w_{F}=\underline{w}$. With $q=0$, the lender must give a carrot $\left(w_{S}-w_{F}\right)$ equal to the amount of discretion $(\Delta)$ to satisfy $\left(I C_{S F}\right)$; when $q=\bar{q}(\Delta)$, instead, the contract induces truthtelling by using only stick since $w_{S}=w_{F}=\underline{w}$. In order to see which method between the carrot and the stick performs better, we compare the extra financing cost generated by the supervisor's moral hazard with respect to the cost in the absence of the moral hazard. Without the moral hazard, the financing cost is simply $\rho+\underline{w}$. The extra cost under the carrot contract is $p \Delta$ while the extra cost under the stick contract is $(1-p) \bar{q}(\Delta) k=(1-p) \Delta k /(\Delta+\underline{w})$. The two are the same when $\Delta=\bar{\Delta}$, but the former increases faster than the latter as $\Delta \geq \bar{\Delta}$ increases. Hence, using only an incentive pay is optimal for small discretion $(\Delta \leq \bar{\Delta})$ while using only audit is optimal for large discretion $(\Delta \geq \bar{\Delta})$. For expositional facility, we say that a supervisory contract belongs to the stick regime when $\Delta \geq \max \{0, \bar{\Delta}\}$ and to the carrot regime when $0 \leq \Delta \leq \max \{0, \bar{\Delta}\}$. Note however that in the special case of $\Delta=0$, lemma 2(ii) says that the lender needs neither carrot nor stick.

\subsection{The optimal lending contract}

We now find the optimal lending contract by maximizing the borrower's payoff subject to the lender's break-even constraint $(B E)$. Given a lending contract $\left\{r_{S}, r_{F}\right\}$, proposition 1 identifies the minimum financing cost that determines the right hand side of $(B E)$. Furthermore, since any increase in $r_{S}$ or $r_{F}$ reduces the borrower's payoff, $(B E)$ must bind in the optimum. We first find the optimal lending contract conditional on the carrot or the stick regime and then derive the optimal contract. 
Consider first the carrot regime, which occurs if $0 \leq \Delta \leq \max \{0, \bar{\Delta}\}$. Then, from the binding $(B E)$, we obtain

$$
r_{F}=\rho+\underline{w} .
$$

Since $r_{F}$ is equal to $\rho+\underline{w}$ regardless of the value of $\Delta$, the objective of $\left(L^{S}\right)$ is given by

$$
p\left(Y_{S}-\rho-\underline{w}-\Delta\right)-(1-p) \psi(\rho+\underline{w}) .
$$

It is clear that $\Delta>0$ increases the financing cost (with respect to $\Delta=0$ ) without affecting $r_{F}$; hence, in the carrot regime a rigid contract (a contract with $\Delta=0$ ) is optimal. This implies $r_{S}=r_{F}=\rho+\underline{w}$.

Consider now the stick regime, which occurs if $\Delta \geq \max \{0, \bar{\Delta}\}$. Now the binding $(B E)$ is given by

$$
r_{F}=\rho+\underline{w}+(1-p) \bar{q}(\Delta) k-p \Delta\left(\equiv r_{F}^{\text {stick }}(\Delta)\right) \text {. }
$$

Since $r_{F}$ cannot be negative, a value of $\Delta$ satisfying $\Delta \geq \max \{0, \bar{\Delta}\}$ is feasible if and only if $r_{F}^{\text {stick }}(\Delta) \geq 0$. It is easy to verify that $r_{F}^{\text {stick }}\left(\Delta^{\max }\right)=0$, where $\Delta^{\text {max }}$ is defined through (2), and that $r_{F}^{\text {stick }}$ is decreasing in $\Delta$ because

$$
\frac{d r_{F}^{s t i c k}}{d \Delta}=(1-p) \frac{\underline{w}}{(\Delta+\underline{w})^{2}} k-p<0 \quad \text { for any } \Delta \geq \max \{0, \bar{\Delta}\} .
$$

Hence, $r_{F}^{\text {stick }}(\Delta) \geq 0$ if and only if $\Delta \in\left[\max \{0, \bar{\Delta}\}, \Delta^{\max }\right]$. The lender chooses $\Delta$ in this interval to maximize the following objective of $\left(L^{S}\right)$ :

$$
p\left[Y_{S}-r_{F}^{s t i c k}(\Delta)-\Delta\right]-(1-p) \psi\left[r_{F}^{\text {stick }}(\Delta)\right] .
$$

Let $\Delta^{* S}$ denote the maximizer of (7). In order to have an idea of what determines $\Delta^{* S}$, notice from (6) that an increase in $\Delta$ has two opposing effects on $r_{F}^{s t i c k}$. On the one hand, $r_{F}^{s t i c k}$ is reduced because of the term $-p \Delta$ which shifts the borrower's payment from state $F$ to state $S$ without changing his expected payment; this increases his payoff by providing insurance (see lemma 1 ). On the other hand, increasing $\Delta$ raises the auditing cost because, for a given $q<1$, it gives the supervisor a higher incentive to embezzle and a larger $q$ is needed to satisfy $\left(I C_{S F}\right)$ with $w_{S}=\underline{w}$. This increases $r_{F}^{s t i c k}$ through the term $(1-p) \bar{q}(\Delta) k$ and reduces the borrower's payoff. This trade-off makes it difficult to find the exact value of $\Delta^{* S}$, as it results from $f(\Delta) \equiv-p\left[\frac{d r_{F}^{\text {stick }}(\Delta)}{d \Delta}+1\right]-(1-p) \psi^{\prime}\left[r_{F}^{\text {stick }}(\Delta)\right] \frac{d r_{F}^{\text {stick }}(\Delta)}{d \Delta}$, the first order derivative of (7).

The next proposition characterizes the optimal grand contract; after summarizing the general finding in (i), it gives more detailed results by considering specific cases in (ii) and 
(iii). Since, without further assumption, it is impossible to derive $\Delta^{* S}$ and to perform the comparison between the optimal rigid contract and the optimal discretionary contract, we need to consider the specific cases in which $\psi$ is linear or $\underline{w}=0$.

Proposition 2 When there is a single borrower, under A1,

(i) The optimal grand contract is the best one between the two following ones:

a. a rigid lending contract $\left\{r_{S}=r_{F}=\rho+\underline{w}\right\}$ with $\left\{w_{S}=w_{F}=\underline{w}, q=0\right\}$

b. a lending contract $\left\{r_{S}=\Delta^{* S}+r_{F}, r_{F}=r_{F}^{\text {stick }}\left(\Delta^{* S}\right)\right\}$ with $\left\{w_{S}=w_{F}=\underline{w}, q=\bar{q}\left(\Delta^{* S}\right)\right\}$, which is discretionary if $\Delta^{* S}>0$.

(ii) When $\psi(r)=\theta r$ with $\theta>1$, we find that $\Delta^{* S} \in\left\{\max \{0, \bar{\Delta}\}, \Delta^{\max }\right\}$. The rigid lending contract is optimal if and only if

$$
k \bar{q}\left(\Delta^{\max }\right) \geq \psi(\rho+\underline{w})-\rho-\underline{w}
$$

Otherwise, the discretionary contract in (i)b with $\Delta^{* S}=\Delta^{\max }$ is optimal.

(iii) When $\underline{w}=0$, we find $\Delta^{* S}=\Delta^{\max }=[\rho+(1-p) k] / p$ and $\bar{q}(\Delta)=1$. Thus, the rigid contract is optimal if and only if $k \geq \psi(\rho)-\rho$, otherwise the discretionary contract in (i)b with $\Delta^{* S}=\Delta^{\max }$ and $q=1$ is optimal.

Suppose that $\psi(r)=\theta r$ for some $\theta>1$. Then, since $r_{F}^{\text {stick }}$ is concave in $\Delta,(7)$ is convex in $\Delta$ and thus $\Delta^{* S}$ is either equal to $\max \{0, \bar{\Delta}\}$ or to $\Delta^{\max }{ }^{29}$ However, if $\Delta^{* S}=\bar{\Delta}$, then the rigid lending contract in Proposition 2(i)a is optimal because we already know that $\Delta=0$ is strictly better than $\Delta=\bar{\Delta}$. Therefore, the rigid contract is optimal if and only if (5) evaluated at $\Delta=0$ is larger than (7) evaluated at $\Delta=\Delta^{\max }$, a condition which is equivalent to (8).

Proposition 2(ii) establishes that when $\psi$ is linear, the optimal lending contract is either a rigid contract or a contract with maximum discretion and stick. In the former case, the lender needs neither carrot nor stick and therefore the financing costs are equal to $\rho+\underline{w}$, the lowest feasible level. However, $r_{F}=\rho+\underline{w}>0$ implies that the borrower is badly insured. The contract with maximum discretion instead provides full insurance because it specifies $r_{S}=\Delta^{\max }(>0)$ and $r_{F}=0$. However, the possibility of embezzlement requires the lender to conduct audit with probability $\bar{q}\left(\Delta^{\max }\right) \in(0,1)$ whenever the supervisor reports that the project failed and this increases the borrower's expected payment to

\footnotetext{
${ }^{29}$ We obtain the corner solutions since the marginal gain in terms of insurnace from increasing $\Delta$ is constant because of the linear $\psi(r)$ while the marginal cost in terms of audit cost decreases because of concave $\bar{q}(\Delta)$.
} 
$\rho+\underline{w}+(1-p) k \bar{q}\left(\Delta^{\max }\right)$. Therefore, it is obvious that the optimal lending contract is rigid if and only if the expected audit cost $(1-p) k \bar{q}\left(\Delta^{\max }\right)$ is larger than the expected gain $(1-p)[\psi(\rho+\underline{w})-\rho-\underline{w}]$ from full insurance, as stated by $(8) .{ }^{30}$

Another setting in which a clear result can be obtained is the one with $\underline{w}=0$; then, we have $\bar{\Delta}>0$ and $\bar{q}(\Delta)=1$ for any $\Delta \geq \bar{\Delta}$. In this case, since an increase of $\Delta$ in $\left[\bar{\Delta}, \Delta^{\mathrm{max}}\right]$ does not increase the audit cost but reduces $r_{F}^{\text {stick }}$ (and increases $r_{S}$ ) without modifying the borrower's expected payment, it is clear that $\Delta^{* S}=\Delta^{\text {max }}$, which is equal to $[\rho+(1-p) k] / p$. Then, the same argument given above about the trade-off between insurance and audit cost determines the optimum between the rigid contract and the contract with maximum discretion.

Remark 1 The characterization of the optimal contract in proposition 2 applies even if $r_{F}$ can be negative. First, the optimal rigid contract is obviously not affected. Second, concerning the optimal discretionary contract, setting $r_{F}<0$ does not improve insurance provision with respect to $r_{F}=0$ but weakly increases the audit cost $k \bar{q}(\Delta)$ since $\Delta$ must be larger than $\Delta^{\max }$.

\section{Group lending}

Suppose now that there are two borrowers living in the same village. Each borrower finances a project with one unit of money borrowed from the lender and a supervisor monitors both of them. For simplicity, we assume that the revenue of each project is identically and independently distributed. Let $p \in(0,1)$ denote the probability of success of a project. We assume that both borrowers and the supervisor observe whether each project succeeds or fails. We distinguish two cases depending on whether there is joint liability or individual liability between the two borrowers.

Under individual liability, the lender signs an individual lending contract with each borrower which takes the same form $\left\{r_{S}, r_{F}\right\}$ as before. However, the supervisory contract is different since the supervisor now monitors two borrowers. Let $w_{n}$ represent the supervisor's wage and $q_{n}$ the probability of conducting an audit when he reports that $n$ number of projects succeeded, with $n \in\{0,1,2\}$. Therefore, a supervisory contract is given by $\left\{w_{n}, q_{n}\right.$, for $\left.n=0,1,2\right\}$; the minimum wage constraint requires $w_{n} \geq \underline{w}$ for each $n$. Since both borrowers live in the same village, the cost of audit does not depend on

\footnotetext{
${ }^{30}$ Actually, proposition 2(ii) holds as long as (7) is convex in $\Delta$, which occurs even though $\psi$ is not linear but $\psi^{\prime \prime}$ is close to 0 .
} 
whether the lender audits the payment of one borrower or those of both borrowers ${ }^{31}$ and is equal to $k>0$.

Introducing joint liability affects the form of the lending contract but not the form of the supervisory contract. Under joint liability, the lender signs a lending contract with the group of the two borrowers which takes the form $\left\{r_{S S}, r_{S F}, r_{F S}, r_{F F}\right\}^{32}$ where, for instance, $r_{S F}$ represents the payment that a borrower whose project succeeded has to make when the other's project failed. Without loss of generality, we assume that $r_{i j}$ cannot be negative for $i, j=S, F{ }^{33}$

We call a lending contract with joint liability a group lending contract. Note first that the set of lending contracts under individual liability can be seen as the (strict) subset of the group lending contracts that satisfy $r_{S S}=r_{S F}$ and $r_{F S}=r_{F F}$. Observe also that if the supervisor is honest, the first-best outcome can be achieved under individual liability by choosing $p r_{S}=\rho+\underline{w}$ and $r_{F}=0$. Therefore, we have two observations:

Observation 1: The set of lending contracts under individual liability is a strict subset of the set of group lending contracts.

Observation 2: If the supervisor is honest, the first-best outcome can be achieved without joint liability.

We define a rigid or a discretionary group lending contract:

Definition: A group lending contract is rigid if $2 r_{S S}=r_{S F}+r_{F S}=2 r_{F F}$; otherwise, it is discretionary.

In this section we make the following assumption, where $\Delta_{1}^{\max }$ denotes the largest solution of

$$
\rho+\frac{1}{2} \underline{w}+\frac{(1-p)^{2} k}{2} \frac{\Delta_{1}}{\Delta_{1}+\underline{w}}=\frac{p(2-p)}{2} \Delta_{1}
$$

A1': We assume (i) $p Y_{S}>\rho+\frac{1}{2} \underline{w}+(1-p) \min \left\{\psi\left(\rho+\frac{1}{2} \underline{w}\right)-\rho-\frac{1}{2} \underline{w}, \frac{1+p}{2} k\right\}$ and (ii) $Y_{S} \geq \Delta_{1}^{\max }$.

\footnotetext{
${ }^{31}$ The main cost of audit is the cost of visiting the village and the marginal cost of visiting one more borrower in the same village is negligeable.

${ }^{32}$ In the literature, joint liability has often been formalized as in our paper.

${ }^{33} \mathrm{As}$ in the case of the single borrower, we can obtain our results even though $r_{i j}$ can be negative but considering this possibility makes the proofs much longer. Even though the constraint $r_{F F} \geq 0$ binds in our analysis, one cannot strictly improve the borrowers' payoff by allowing for $r_{F F}<0$ for reasons similar to those explained in remark 1 in section 3.
} 
A1'(i) is similar to A1 and implies that the NPV of the project is positive at the equilibrium. A1'(ii) simplifies our analysis of the optimal lending contract under joint liability in that $r_{F S}=0$ becomes optimal; it is introduced since otherwise the characterization of the optimal supervisory and lending contracts under joint liability is technically more demanding without generating any new insight. Note that both A1'(i) and A1'(ii) are equivalent to requiring that $Y_{S}$ be large enough.

Consider the case of joint liability. As we have argued in section 3, by the revelation principle there is no loss of generality in restricting our attention to direct revelation mechanisms that induce the supervisor to report the true state. Therefore, the following incentive constraints should be satisfied:

$$
\left(\mathrm{IC}_{n \widehat{n}}\right) \quad w_{n} \geq\left(1-q_{\widehat{n}}\right)\left[R(n)-R(\widehat{n})+w_{\widehat{n}}\right] \quad \text { for } \quad(n, \widehat{n}) \in\{0,1,2\}^{2},
$$

where $R(2) \equiv 2 r_{S S}, R(1) \equiv r_{S F}+r_{F S}, R(0) \equiv 2 r_{F F}$. The lender's break-even constraint is now

$$
\begin{aligned}
& (B E) \quad 2 p^{2} r_{S S}+2 p(1-p)\left(r_{S F}+r_{F S}\right)+2(1-p)^{2} r_{F F} \\
\geq & 2 \rho+p^{2}\left(w_{2}+k q_{2}\right)+2 p(1-p)\left(w_{1}+k q_{1}\right)+(1-p)^{2}\left(w_{0}+k q_{0}\right)
\end{aligned}
$$

and the lender's program under joint liability, denoted by $\left(L^{J}\right)$, is defined as follows:

$$
\max _{\substack{r_{S S}, r_{S F}, r_{F S}, r_{F F} \\ w_{n}, q_{n} \text { for } n=0,1,2}} p^{2}\left(2 Y_{S}-2 r_{S S}\right)+2 p(1-p)\left(Y_{S}-r_{S F}-\psi\left(r_{F S}\right)\right)-(1-p)^{2} 2 \psi\left(r_{F F}\right)
$$

$$
(B E),(10), r_{i j} \geq \quad \begin{aligned}
& \text { subject to } \\
& 0 \text { for } i, j=S, F, w_{n} \geq \underline{w} \text { for } n=0,1,2 .
\end{aligned}
$$

Note that in the objective function in $\left(L^{J}\right)$ we assume $r_{S F} \leq Y_{S}$ and $r_{S S} \leq Y_{S}$, which in the proof of proposition 4 we verify to be satisfied under A1'.

Our next lemma presents one important effect of joint liability:

Lemma 3 When there are two borrowers, under joint liability, it is optimal to choose $r_{F S}=0$ and $r_{S F}=R(1)$ if $Y_{S}$ is sufficiently large.

Proof. Let $R(1)$ be given, which means that $r_{S F}+r_{F S}$ is given. We prove that if $Y_{S}$ is sufficiently large, then it is optimal to set $r_{F S}=0$ and thus $r_{S F}=R(1)$. Since $R(1)$ is given, $\left(r_{S F}, r_{F S}\right)$ does not affect (10) but affects the borrowers' payoff only through the term

$$
2 p(1-p)\left[Y_{S}-r_{S F}-\psi\left(r_{F S}\right)\right]=2 p(1-p)\left[Y_{S}-R(1)+r_{F S}-\psi\left(r_{F S}\right)\right]
$$


where the equality comes from $r_{S F}=R(1)-r_{F S}$. In writing (11), we implicitly assumed that $r_{S F} \leq Y_{S}$. As long as this condition holds, maximizing (11) with respect to $r_{F S}$ tells us that any $r_{F S}>0$ is dominated by $r_{F S}=0$ since $\psi^{\prime}(r)>1$ for any $r>0$. We prove in proposition 4 that the condition $r_{S F} \leq Y_{S}$ is satisfied in the optimal lending contract given that A1'(ii) holds. ${ }^{34}$

Lemma 3 says that when one borrower is successful and the other is not, it is optimal that the unsuccessful borrower pays nothing $\left(r_{F S}=0\right)$ and the lender's revenue comes only from the successful borrower $\left(r_{S F}=R(1)\right)$. The reason is that letting the unsuccessful borrower pay a positive amount requires him to reduce his consumption, which is more costly for borrowers than simply using the money generated by the successful project. Therefore, joint liability provides borrowers with insurance in the states of the world where only one project is successful. Clearly, this approach is viable only if the successful borrower has enough money to pay $R(1)$; we show later on that $R(1) \leq Y_{S}$ holds in the optimal contract under A1'.

Let $\Delta_{1} \equiv r_{S F}+r_{F S}-2 r_{F F}$ and $\Delta_{2} \equiv 2 r_{S S}-r_{S F}-r_{F S}$. For the case of one borrower, lemma 1(ii) shows that the optimal lending contract is such that $\Delta \geq 0$. For the time being we analyze the setting with two borrowers by focusing on the case in which $\Delta_{1} \geq 0$ and $\Delta_{2} \geq 0$. After deriving the optimal grand contract when $\Delta_{1} \geq 0$ and $\Delta_{2} \geq 0$, we prove that relaxing these restrictions on $\left(\Delta_{1}, \Delta_{2}\right)$ does not increase the borrowers' payoff (in lemma 8).

The program with individual liability, denoted by $\left(L^{I}\right)$, is defined as $\left(L^{J}\right)$ except that $r_{S}$ replaces $r_{S S}$ and $r_{S F}$ and $r_{F}$ replaces $r_{F F}$ and $r_{F S}$ (and therefore we have $\Delta_{1}=\Delta_{2}$ ). Notice that under individual liability the proof of lemma 1(ii) applies and therefore we consider only lending contracts with $r_{S}-r_{F} \geq 0$.

In $\left(L^{J}\right)$, when $\Delta_{1} \geq 0$ and $\Delta_{2} \geq 0$, it is easy to see that the supervisor has no incentive to report a state $\widehat{n}$ larger than the true state $n$ in the absence of any incentive pay or audit. Therefore, we consider a relaxed problem $\left(L r^{J}\right)$ in which the upward incentive constraints $\left(\mathrm{IC}_{02}\right),\left(\mathrm{IC}_{01}\right),\left(\mathrm{IC}_{12}\right)$ are neglected and $\left(w_{0}, w_{1}, w_{2}, q_{0}, q_{1}, q_{2}\right)$ need to satisfy only (12)-(13):

$$
\left\{\begin{array}{c}
\left(\mathrm{IC}_{21}\right) \quad w_{2} \geq\left(1-q_{1}\right)\left(\Delta_{2}+w_{1}\right) ; \\
\left(\mathrm{IC}_{20}\right) \quad w_{2} \geq\left(1-q_{0}\right)\left(\Delta_{2}+\Delta_{1}+w_{0}\right) ; \\
\left(\mathrm{IC}_{10}\right) \quad w_{1} \geq\left(1-q_{0}\right)\left(\Delta_{1}+w_{0}\right) ;
\end{array}\right.
$$

\footnotetext{
${ }^{34}$ Furthermore, if we allow for $r_{F S}<0$ then (11) becomes $2 p(1-p)\left[Y_{S}-R(1)\right]$ and does not depend on $r_{F S}$. Intuitively, in state $F S$ the marginal utility of money for the unsuccessful borrower is 1 when $r_{F S}<0$ and so the precise value of $r_{F S}(<0)$ is irrelevant, given $R(1)$. However, since $r_{S F}=R(1)-r_{F S}$, a negative $r_{F S}$ makes $r_{S F}$ larger than $R(1)$ and it is more difficult to satisfy $r_{S F} \leq Y_{S}$.
} 


$$
(L L) \quad w_{n} \geq \underline{w} \quad \text { for } \quad n=0,1,2 .
$$

The next lemma establishes some straightforward properties of $\left(L r^{J}\right)$ and, more importantly, shows that the solution to $\left(L r^{J}\right)$ satisfies $\left(\mathrm{IC}_{02}\right),\left(\mathrm{IC}_{01}\right),\left(\mathrm{IC}_{12}\right)$ even though we do not know yet the solution. Therefore, the solution to $\left(L r^{J}\right)$ is the optimal grand contract and, with some abuse of notation, we use $\left(L^{J}\right)$ to denote the relaxed problem.

Lemma 4 The solution to the relaxed problem

(i) is such that $q_{2}=0$ and $w_{0}=\underline{w}$;

(ii) satisfies $\left(I C_{02}\right),\left(I C_{01}\right),\left(I C_{12}\right)$ and therefore it is just the optimal grand contract.

As in the previous section, we perform our analysis in two steps: we first find the optimal supervisory contract given a lending contract and then find the optimal lending contract.

\subsection{The optimal supervisory contract}

In this subsection, we find the optimal supervisory contract, given a lending contract $\left\{r_{S S}, r_{S F}, r_{F S}, r_{F F}\right\}$ satisfying $\left(\Delta_{1}, \Delta_{2}\right) \geq(0,0)$, by minimizing the right hand side of (BE) with respect to $\left(w_{2}, w_{1}, q_{1}, q_{0}\right)$ subject to (12)-(13). Let $\left(S^{J}\right)$ denote this program:

$$
\begin{gathered}
\min _{w_{2}, w_{1}, q_{1}, q_{0}} 2 \rho+p^{2} w_{2}+2 p(1-p)\left(w_{1}+k q_{1}\right)+(1-p)^{2}\left(\underline{w}+k q_{0}\right) \\
\text { subject to }(12)-(13)
\end{gathered}
$$

We use $C^{J}\left(\Delta_{1}, \Delta_{2}\right)$ to represent the value of the objective function in (14) at the optimal supervisory contract.

Solving $\left(S^{J}\right)$ is not straightforward because the incentive constraints are not linear in $\left(w_{2}, w_{1}, q_{1}, q_{0}\right)$, although they are linear in each single variable. This leads to minimizing a function which is neither concave nor convex, over a non-convex feasible set. We first prove that there exist three regimes for the binding incentive constraints in the solution to $\left(S^{J}\right)$ :

Lemma 5 When there are two borrowers, under joint liability, the optimal supervisory contract given $\left(\Delta_{1}, \Delta_{2}\right) \geq(0,0)$ is such that the binding incentive constraints are either $\left(I C_{21}\right)$ and $\left(I C_{20}\right)$, or $\left(I C_{10}\right)$ and $\left(I C_{21}\right)$, or all the three constraints in (12)

The next lemma shows that by considering the three regimes, five different supervisory contracts may be optimal for different parameter values. The contracts are introduced below and are denoted by $\alpha, \beta, \gamma, \delta, \eta ; C_{h}^{J}\left(\Delta_{1}, \Delta_{2}\right)$ represents the value of the objective function in (14) under contract $h=\alpha, \beta, \gamma, \delta, \eta$. 
- $\alpha:\left(q_{0}, q_{1}\right)=(0,0), \quad\left(w_{0}, w_{1}, w_{2}\right)=\left(\underline{w}, \underline{w}+\Delta_{1}, \underline{w}+\Delta_{1}+\Delta_{2}\right), \quad C_{\alpha}^{J}\left(\Delta_{1}, \Delta_{2}\right)=$ $2 \rho+\underline{w}+p(2-p) \Delta_{1}+p^{2} \Delta_{2}$

- $\beta:\left(q_{0}, q_{1}\right)=\left(\frac{\Delta_{1}}{\Delta_{1}+\underline{w}}, 0\right), \quad\left(w_{0}, w_{1}, w_{2}\right)=\left(\underline{w}, \underline{w}, \underline{w}+\Delta_{2}\right), \quad C_{\beta}^{J}\left(\Delta_{1}, \Delta_{2}\right)=2 \rho+\underline{w}+$ $(1-p)^{2} k \frac{\Delta_{1}}{\Delta_{1}+\underline{w}}+p^{2} \Delta_{2}$

- $\gamma:\left(q_{0}, q_{1}\right)=\left(\frac{\Delta_{1}}{\Delta_{1}+\underline{w}}, \frac{\Delta_{2} \Delta_{1}}{\left(\Delta_{2}+\underline{w}\right)\left(\Delta_{1}+\underline{w}\right)}\right), \quad\left(w_{0}, w_{1}, w_{2}\right)=\left(\underline{w}, \underline{w}, \underline{w}+\underline{w} \frac{\Delta_{2}}{\Delta_{1}+\underline{w}}\right), \quad C_{\gamma}^{J}\left(\Delta_{1}, \Delta_{2}\right)=$ $2 \rho+\underline{w}+p^{2} \underline{w} \frac{\Delta_{2}}{\Delta_{1}+\underline{w}}+2 p(1-p) k \frac{\Delta_{2} \Delta_{1}}{\left(\Delta_{2}+\underline{w}\right)\left(\Delta_{1}+\underline{w}\right)}+(1-p)^{2} k \frac{\Delta_{1}}{\Delta_{1}+\underline{w}}$

- $\delta::^{35} q_{0}=q_{0}^{*} \equiv 1+\frac{\Delta_{2}}{\Delta_{1}+\underline{w}}-\frac{1}{\Delta_{1}+\underline{w}} \sqrt{\frac{2 p(1-p) k \Delta_{2}\left(\Delta_{2}+\Delta_{1}+\underline{w}\right)}{p\left(p \Delta_{2}+(2-p)\left(\Delta_{1}+\underline{w}\right)\right)-(1-p)^{2} k}}, q_{1}=f\left(q_{0}^{*}\right)$ with $f\left(q_{0}\right) \equiv$ $\frac{q_{0} \Delta_{2}}{\Delta_{2}+\left(1-q_{0}\right)\left(\Delta_{1}+\underline{w}\right)},\left(w_{0}, w_{1}, w_{2}\right)=\left(\underline{w}, \underline{w}+\left(1-q_{0}^{*}\right)\left(\Delta_{1}+\underline{w}\right), \underline{w}+\left(1-q_{0}^{*}\right)\left(\Delta_{1}+\Delta_{2}+\underline{w}\right)\right)$, $C_{\delta}^{J}\left(\Delta_{1}, \Delta_{2}\right)=2 \rho+\left(1-q_{0}^{*}\right)\left[p^{2} \Delta_{2}+(2-p) p\left(\Delta_{1}+\underline{w}\right)\right]+2 p(1-p) k f\left(q_{0}^{*}\right)+(1-$ $p)^{2}\left(k q_{0}^{*}+\underline{w}\right)$.

- $\eta:\left(q_{0}, q_{1}\right)=\left(\frac{\Delta_{2}+\Delta_{1}}{\Delta_{2}+\Delta_{1}+\underline{w}}, \frac{\Delta_{2}}{\Delta_{2}+\underline{w}}\right), \quad\left(w_{0}, w_{1}, w_{2}\right)=(\underline{w}, \underline{w}, \underline{w}), \quad C_{\eta}^{J}\left(\Delta_{1}, \Delta_{2}\right)=2 \rho+\underline{w}+$ $2 p(1-p) k \frac{\Delta_{2}}{\Delta_{2}+\underline{w}}+(1-p)^{2} k \frac{\Delta_{2}+\Delta_{1}}{\Delta_{2}+\Delta_{1}+\underline{w}}$.

We have:

Lemma 6 When there are two borrowers, under joint liability,

(i) Suppose that $\Delta_{1}>0$ and $\Delta_{2}>0$.

a. If only $\left(I C_{21}\right)$ and $\left(I C_{20}\right)$ bind in the optimum of $\left(S^{J}\right)$, then $\eta$ is the optimal supervisory contract.

b. If only $\left(I C_{10}\right)$ and $\left(I C_{21}\right)$ bind in the optimum of $\left(S^{J}\right)$, then $\beta$ is the optimal supervisory contract.

c. If all the constraints in (12) bind in the optimum of $\left(S^{J}\right)$, then the optimal supervisory contract belongs to $\{\alpha, \delta, \gamma\}$.

(ii) If $\Delta_{1}=0$ and/or $\Delta_{2}=0$, then the optimal supervisory contract belongs to $\{\alpha, \beta, \eta\}$.

A consequence of lemma 6 is the following proposition, which characterizes the optimal supervisory contract for any given lending contract with $\Delta_{1} \geq 0$ and $\Delta_{2} \geq 0$. The proposition includes the characterization of the optimal supervisory contract under individual liability as a special case with $\Delta_{1}=\Delta_{2} \geq 0$.

Proposition 3 When there are two borrowers, under joint liability, the optimal supervisory contract is the lowest cost contract among $\alpha, \beta, \gamma, \delta, \eta$. Hence, $C^{J}\left(\Delta_{1}, \Delta_{2}\right) \equiv$ $\min \left\{C_{\alpha}^{J}\left(\Delta_{1}, \Delta_{2}\right), C_{\beta}^{J}\left(\Delta_{1}, \Delta_{2}\right), C_{\gamma}^{J}\left(\Delta_{1}, \Delta_{2}\right), C_{\delta}^{J}\left(\Delta_{1}, \Delta_{2}\right), C_{\eta}^{J}\left(\Delta_{1}, \Delta_{2}\right)\right\}$.

\footnotetext{
${ }^{35}$ This contract is defined if and only if $2 p(1-p) \frac{\Delta_{2}}{\Delta_{2}+\Delta_{1}+\underline{w}} k<p\left(p \Delta_{2}+(2-p)\left(\Delta_{1}+\underline{w}\right)\right)-(1-p)^{2} k<$ $2 p(1-p) \frac{\Delta_{2}\left(\Delta_{2}+\Delta_{1}+\underline{w}\right)}{\left(\Delta_{2}+\underline{w}\right)^{2}} k$; these conditions are equivalent to $q_{0}^{*} \in\left(0, \frac{\Delta_{1}}{\Delta_{1}+\underline{w}}\right)$.
} 
To give an interpretation of each different supervisory contract, we consider the simple case of $\underline{w}=0$; then, contract $\eta$ is equivalent to $\gamma$. Contract $\alpha$ specifies no audit but intensively uses carrots since $w_{1}-w_{0}=\Delta_{1}$ and $w_{2}-w_{1}=\Delta_{2}$. Contract $\gamma$, by contrast, gives no incentive pay but intensively uses sticks since the lender conducts audit with probability one whenever the supervisor reports that at least one project failed. Contract $\beta$ uses either carrot or stick depending on the supervisor's report in the following sense. When the supervisor reports $n=0$, the lender audits with probability one $\left(q_{0}=1\right)$ while the supervisor receives a carrot $w_{2}-w_{1}=\Delta_{2}$ when he reports $n=2$. Finally, contract $\delta$ mixes carrots and sticks not over different states of nature as $\beta$, but within the same state of nature; since $\Delta_{1}>w_{1}-w_{0}>0$ and $\Delta_{2}>w_{2}-w_{1}>0$, there is a positive probability of audit both if the supervisor reports $n=1$ and if he reports $n=0$.

\subsection{The optimal lending contract under joint liability}

In this subsection we find the optimal lending contract under joint liability by solving $\left(L^{J}\right)$. When $\Delta_{1} \geq 0$ and $\Delta_{2} \geq 0$, the next lemma says that we can restrict our attention to the set of lending contracts satisfying $\Delta_{2}=0$.

Lemma 7 If $Y_{S}$ is sufficiently large, then the best contract within the set of lending contracts satisfying $\Delta_{1} \geq 0$ and $\Delta_{2} \geq 0$ is such that $\Delta_{2}=0$. Thus, the best supervisory contract is either $\alpha$ or $\beta$.

The proof of the lemma basically shows that when $\Delta_{1} \geq 0$ and $\Delta_{2}>0$, reducing $\Delta_{2}$ while increasing $\Delta_{1}$ and keeping the borrowers' expected payment constant does not hurt borrowers but can relax the incentive constraints in (12). ${ }^{36}$ Since $\Delta_{2}=0$ implies that (i) $\delta$ is not defined (see footnote 35); (ii) $\gamma$ and $\eta$ are equivalent to $\beta$, it follows that the optimal supervisory contract belongs to $\{\alpha, \beta\}$.

In order to solve $\left(L^{J}\right)$, we first determine $C^{J}\left(\Delta_{1}, 0\right)$ by comparing $C_{\alpha}^{J}\left(\Delta_{1}, 0\right)$ with $C_{\beta}^{J}\left(\Delta_{1}, 0\right)$. For this purpose, we introduce $\bar{\Delta}_{1} \equiv \frac{(1-p)^{2}}{p(2-p)} k-\underline{w} \cdot{ }^{37}$ Then, it turns out that for $\Delta_{1} \in\left[0, \max \left\{0, \bar{\Delta}_{1}\right\}\right]$, contract $\alpha$ is optimal and therefore we are in the carrot regime. By contrast, if $\Delta_{1}>\max \left\{0, \bar{\Delta}_{1}\right\}$, contract $\beta$ is optimal and we are in the stick regime.

\footnotetext{
${ }^{36} \mathrm{As}$ for lemma 3 , this argument assumes that $Y_{S}$ is larger than $R(1)$. We verify in the proof of proposition 4 that this condition is satisfied.

${ }^{37}$ Note that $\bar{\Delta}_{1}$ is similar to $\bar{\Delta}$ defined in section 3.1 in that $k$ is multiplied by the probability of the state in which audit may occur in contract $\beta$ and is divided by the probability of the states in which there is no audit.
} 
We now derive the optimal lending contract while assuming that $Y_{S}$ is large enough. By using $r_{S F}=2 r_{S S}=\Delta_{1}+2 r_{F F}\left(r_{F S}=0\right.$ by lemma 3 and $\Delta_{2}=0$ by lemma 7$)$ we can write the lender's program as follows:

$$
\max _{\Delta_{1} \geq 0, r_{F F} \geq 0} 2 p Y_{S}-p(2-p)\left(2 r_{F F}+\Delta_{1}\right)-(1-p)^{2} 2 \psi\left(r_{F F}\right)
$$

subject to

$$
(B E) \quad 2 r_{F F}+p(2-p) \Delta_{1}=C^{J}\left(\Delta_{1}, 0\right) ;
$$

since $(B E)$ binds in the optimum in the case of two borrowers as well.

Consider first the carrot regime (i.e. $\left.\Delta_{1} \in\left[0, \max \left\{0, \bar{\Delta}_{1}\right\}\right]\right)$. Then, (16) is equivalent to $2 r_{F F}=2 \rho+\underline{w}$. Since increasing $\Delta_{1}$ ends up only increasing the financing cost without improving insurance provision, it is optimal to choose $\Delta_{1}=0$ in the carrot regime as in the case of single borrower.

Consider now the stick regime (i.e. $\Delta_{1} \geq \max \left\{0, \bar{\Delta}_{1}\right\}$ ). Then (16) is equivalent to

$$
r_{F F}=\rho+\frac{w}{2}+\frac{(1-p)^{2} k}{2} \bar{q}\left(\Delta_{1}\right)-\frac{p(2-p)}{2} \Delta_{1}\left(\equiv r_{F F}^{\text {stick }}\left(\Delta_{1}\right)\right) \text {. }
$$

Since $r_{F F}^{\text {stick }}$ is decreasing for $\Delta_{1} \geq \max \left\{0, \bar{\Delta}_{1}\right\}$ and $r_{F F}^{\text {stick }}\left(\Delta_{1}^{\max }\right)=0\left(\Delta_{1}^{\max }\right.$ has been introduced just before assumption A1'), it follows that $r_{F F}^{s t i c k}\left(\Delta_{1}\right) \geq 0$ if and only if $\Delta_{1} \leq \Delta_{1}^{\max }$. Hence, the lender maximizes with respect to $\Delta_{1} \in\left[\max \left\{0, \bar{\Delta}_{1}\right\}, \Delta_{1}^{\max }\right]$ the following objective:

$$
2 p Y_{S}-p(2-p)\left[2 r_{F F}^{s t i c k}\left(\Delta_{1}\right)+\Delta_{1}\right]-(1-p)^{2} 2 \psi\left[r_{F F}^{s t i c k}\left(\Delta_{1}\right)\right] .
$$

This maximization problem is similar to the one in section 3.2. Let $\Delta_{1}^{* \beta}$ denote the maximizer of $(18)$ in $\left[\max \left\{0, \bar{\Delta}_{1}\right\}, \Delta_{1}^{\max }\right]$. Proposition 4 gives the general result and some clear-cut results under specific assumptions on $\psi$ or $\underline{w}$ as proposition 2 in section 3.2 .

Proposition 4 When there are two borrowers, under A1' and joint liability,

(i) the optimal grand contract is the best between the two following ones:

a. A rigid lending contract $\left\{2 r_{S S}=2 r_{F F}=r_{S F}=2 \rho+\underline{w}, r_{F S}=0\right\}$ with $\left\{q_{0}=q_{1}=\right.$ $\left.q_{2}=0, w_{0}=w_{2}=w_{2}=\underline{w}\right\}$ (the supervisory contract is $\alpha$ ).

b. A lending contract $\left\{2 r_{S S}=r_{S F}=\Delta_{1}^{* \beta}+2 r_{F F}, r_{F S}=0, r_{F F}=r_{F F}^{\text {stick }}\left(\Delta_{1}^{* \beta}\right)\right\}$ with $\left\{q_{0}=\bar{q}\left(\Delta_{1}^{* \beta}\right), q_{1}=q_{2}=0, w_{0}=w_{2}=w_{2}=\underline{w}\right\}$ (the supervisory contract is $\beta$ ), which is discretionary if $\Delta_{1}^{* \beta}>0$.

(ii) When $\psi$ is linear we find that $\Delta_{1}^{* \beta}$ is either equal to $\max \left\{0, \bar{\Delta}_{1}\right\}$ or to $\Delta_{1}^{\max }$. The rigid contract is optimal if and only if $k \bar{q}\left(\Delta_{1}\right) \geq 2\left[\psi\left(\rho+\frac{1}{2} \underline{w}\right)-\rho-\frac{1}{2} \underline{w}\right]$. 
(iii) When $\underline{w}=0$ we obtain $\Delta_{1}^{* \beta}=\Delta_{1}^{\max }=\frac{2 \rho+(1-p)^{2} k}{p(2-p)}$ and the rigid contract is optimal if and only if $k \geq 2(\psi(\rho)-\rho)$.

As in the case of a single borrower, we can determine the exact value of $\Delta_{1}^{* \beta}$ under the assumption that $\psi$ is linear or $\underline{w}=0$. In these cases the optimal contract is either a rigid contract or the contract with maximum discretion in terms of $\Delta_{1}$ (while $\Delta_{2}=0$ from lemma 7 ). The former provides insurance only when at least one project succeeds while the latter provides insurance for all states. However, the latter involves an audit cost; the audit occurs only when both projects fail (and with probability equal to one if $\underline{w}=0)$. Therefore, the rigid contract is optimal when the audit $\operatorname{cost}(1-p)^{2} k \bar{q}\left(\Delta_{1}^{* \beta}\right)$ is superior to the gain $(1-p)^{2} 2\left[\psi\left(\rho+\frac{1}{2} \underline{w}\right)-\rho-\frac{1}{2} \underline{w}\right]$ from providing full insurance for both borrowers, as proposition 4(ii)-(iii) states.

Although the statement of proposition 4 is about the optimal grand contract, proposition 4 considers only lending contracts such that $\Delta_{1} \geq 0$ and $\Delta_{2} \geq 0$. The proposition is correct, nevertheless, since the following lemma shows that there is no loss of generality in restricting attention to contracts with $\Delta_{1} \geq 0$ and $\Delta_{2} \geq 0 .{ }^{38}$

Lemma 8 When there are two borrowers, under joint liability and A1', the optimal lending contract satisfies $\Delta_{1} \geq 0$ and $\Delta_{2} \geq 0$.

\subsection{Individual liability}

In the case of individual liability, a lending contract is such that $r_{S S}=r_{S F}=r_{S}$ and $r_{F S}=r_{F F}=r_{F}$, which implies $\Delta_{1}=\Delta_{2} \equiv \Delta$. In order to have an idea of the effects of individual liability, notice first that in the case of joint liability, given $r_{F F} \geq 0$ and $\Delta_{1} \geq 0$, it is possible to set $r_{F S}=0$ and $r_{S F}=R(1)=2 r_{F F}+\Delta_{1}\left(\right.$ if $2 r_{F F}+\Delta_{1} \leq Y_{S}$ ) and thereby to provide some insurance to an unsuccessful borrower when the other borrower has success (lemma 3). Under individual liability, by contrast, $r_{F S}=0$ implies $r_{F F}=0$ and therefore, for instance, the optimal rigid contract under joint liability described by Proposition 4(i)a is not feasible. Notice also that while it is always optimal to set $\Delta_{2}=0$ under joint liability (lemma 7), in the setting of individual liability no similar result holds because $\Delta_{2}=0$ implies $\Delta_{1}=0$.

The optimal supervisory contract under individual liability is a special case of the optimal supervisory one under joint liability characterized in Proposition 3, after replacing $\Delta_{1}$ and $\Delta_{2}$ with $\Delta$. Therefore, for $h=\alpha, \beta, \gamma, \delta, \eta$, let $C_{h}^{I}(\Delta) \equiv C_{h}^{J}(\Delta, \Delta)$

\footnotetext{
${ }^{38}$ The lemma is presented here because its proof is easier to read after reading the analysis of the case with $\Delta_{1} \geq 0$ and $\Delta_{2} \geq 0$.
} 
denote the cost of the supervisory contract $h$, given $\Delta$. The first part of the next lemma however shows that we can neglect contract $\delta$ (since $\Delta_{1}=\Delta_{2}$ ) and hence we define $C^{I}(\Delta) \equiv \min \left\{C_{\alpha}^{I}(\Delta), C_{\beta}^{I}(\Delta), C_{\gamma}^{I}(\Delta), C_{\eta}^{I}(\Delta)\right\}$ as the minimum financing cost derived from the optimal supervisory contract given $\Delta$. The second part of the lemma proves a useful property of $C^{I}$.

Lemma 9 (i) When there are two borrowers, under individual liability, contract $\delta$ is never an optimal supervisory contract;

(ii) $C^{I}$ is concave in $\Delta$.

From $\left(L^{J}\right)$ we can write the lender's program under individual liability, denoted by $\left(L^{I}\right)$, as follows:

$$
\left\{\begin{array}{cc}
\max _{\Delta \geq 0, r_{F} \geq 0} & 2 p Y_{S}-2 p\left(r_{F}+\Delta\right)-2(1-p) \psi\left(r_{F}\right) \\
\text { subject to } & (B E) \quad 2 r_{F}+2 p \Delta=C^{I}(\Delta)
\end{array}\right.
$$

We can express (19) by using (BE) to obtain $r_{F}(\Delta)=\frac{C^{I}(\Delta)}{2}-p \Delta$, which we insert into the objective function. Furthermore, Lemma 9(ii) implies that there exists a unique $\Delta-$ we represent this value with $\Delta_{I}^{\max }-\operatorname{such}$ that $r_{F}(\Delta) \geq 0$ for $\Delta \in\left[0, \Delta_{I}^{\max }\right]$. Thus, we need to solve the program $\max _{\Delta \in\left[0, \Delta_{I}^{\max }\right]} 2 p Y_{S}-2 p\left(\frac{C^{I}(\Delta)}{2}-p \Delta+\Delta\right)-2(1-p) \psi\left(\frac{C^{I}(\Delta)}{2}-p \Delta\right)$. In order to tackle this program, it would be useful to know, for given $\Delta \in\left[0, \Delta_{I}^{\max }\right]$, which contract in $\{\alpha, \beta, \gamma, \eta\}$ is the optimal supervisory contract. Since comparing the four contracts is cumbersome, we consider the special case in which $\psi$ is linear. Under this assumption the objective function is convex and therefore the optimal contract is either rigid (i.e. $\Delta=0$ ) or has the maximum discretion, in the sense that $r_{F}=0$ and $r_{S}=\Delta_{I}^{\max }$. Notice however that without further specification, it is hard to know the optimal supervisory contract at $\Delta=\Delta_{I}^{\max }$ and hence to determine the value of $\Delta_{I}^{\max }$, which is necessary to have a clear-cut result in terms of comparative static. The next proposition provides a general result under the linear $\psi$ and a more detailed result under the specific case with $\underline{w}=0$.

Proposition 5 When there are two borrowers, under individual liability, suppose that A1' is satisfied and $\psi(r)=\theta r$ with $\theta>1$. Then

(i) The optimal grand contract is the best between the two following ones:

a. A rigid lending contract $\left\{r_{S}=r_{F}=\rho+\frac{1}{2} \underline{w}\right\}$ with $\left\{q_{0}=q_{1}=q_{2}=0, w_{0}=w_{1}=w_{2}=\underline{w}\right\}$,

b. A discretionary contract with $\left\{r_{S}=\Delta_{I}^{\max }, r_{F}=0\right\}$. The rigid contract is optimal if and only if $C^{I}\left(\Delta_{I}^{\max }\right)-C^{I}(0) \geq(1-p)\left\{2 \psi\left[\frac{1}{2} C^{I}(0)\right]-C^{I}(0)\right\}$, where $C^{I}(0)=2 \rho+\underline{w}$. 
(ii) When $\underline{w}=0$ and $2 \rho \geq(1-p)(3-p) k$, the optimal grand contract is the best between the two following ones:

a. A rigid lending contract $\left\{r_{S}=r_{F}=\rho\right\}$ with $\left\{q_{0}=q_{1}=q_{2}=0, w_{0}=w_{1}=w_{2}=0\right\}$ (the supervisory contract is $\alpha$ ).

b. A discretionary contract $\left\{r_{S}=\left[2 \rho+\left(1-p^{2}\right) k\right] / 2 p, r_{F}=0\right\}$ with $\left\{q_{0}=q_{1}=1, q_{2}=0\right.$ $\left.w_{0}=w_{1}=w_{2}=0\right\}$ (the supervisory contract is $\gamma$ with $\left.\Delta=\left[2 \rho+\left(1-p^{2}\right) k\right] / 2 p\right)$. The rigid contract is optimal if and only if $(1+p) k \geq 2(\psi(\rho)-\rho)$.

The result in Proposition 5(i) is quite consistent with Propositions 2(ii) and 4(ii) and shows the trade-off between insurance and the cost to discourage embezzlement. A more specific result can be obtained if, furthermore, we assume that $\underline{w}=0$ because then it is easy to find the optimal supervisory contract given $\Delta$, and so $\Delta_{I}^{\max }$. Indeed, in this case contract $\gamma$ is equivalent to $\eta$ and direct computations show that

$$
C^{I}(\Delta)=\left\{\begin{array}{cc}
2 \rho+2 p \Delta & \text { if } \Delta \leq \frac{(1-p)^{2}}{p(2-p)} k \\
2 \rho+(1-p)^{2} k+p^{2} \Delta & \text { if } \frac{(1-p)^{2}}{p(2-p)} k \leq \Delta \leq \frac{2(1-p)}{p} k \\
2 \rho+\left(1-p^{2}\right) k & \text { if } \frac{2(1-p)}{p} k \leq \Delta
\end{array}\right.
$$

From (20) it follows that $\frac{(1-p)^{2}}{p(2-p)} k<\Delta_{I}^{\max }<\frac{2(1-p)}{p} k$ if $2 \rho<(1-p)(3-p) k$, while $\Delta_{I}^{\max } \geq$ $\frac{2(1-p)}{p} k$ if $2 \rho \geq(1-p)(3-p) k$. We assume in the following that the audit cost is relatively small with respect to the cost of capital and thus $2 \rho \geq(1-p)(3-p) k$ is satisfied $^{39}$ (Remark 2 in this section examines the case in which $\left.2 \rho<(1-p)(3-p) k\right)$. Then $\Delta_{I}^{\max }=\frac{2 \rho+\left(1-p^{2}\right) k}{2 p}>\frac{2(1-p)}{p} k$ and $C^{I}\left(\Delta_{I}^{\max }\right)=C_{\gamma}^{I}\left(\Delta_{I}^{\max }\right)$.

The optimal contract under individual liability characterized in Proposition 5(ii) is very similar to the one in the single-borrower case characterized in Proposition 2(iii). The only difference is that under the optimal discretionary contract in Proposition 5(iii)b, when both borrowers fail, the lender needs to incur the audit cost only once instead of twice. This is why the condition for the optimal contract to be rigid is more restrictive in proposition 5 (ii) than in proposition 2(iii).

Remark 2 When $\underline{w}=0$ and $(1-p)(3-p) k>2 \rho$ holds, we find $\Delta_{I}^{\max }=\frac{2 \rho+(1-p)^{2} k}{p(2-p)}$ and the optimal grand contract is either the rigid one described in proposition 5(ii)a or $\left\{r_{S}=\frac{2 \rho+(1-p)^{2} k}{p(2-p)}, r_{F}=0\right\}$ with $\left\{q_{0}=1, q_{1}=q_{2}=0 \quad w_{0}=w_{1}=0, w_{2}=\frac{2 \rho+(1-p)^{2} k}{p(2-p)}\right\}$ (the supervisory contract is $\beta$ with $\left.\Delta=\frac{2 \rho+(1-p)^{2} k}{p(2-p)}\right)$. The rigid contract is optimal if and only if $p \rho+(1-p)^{2} k \geq(1-p)(2-p)(\psi(\rho)-\rho)$.

\footnotetext{
${ }^{39}$ For instance, if $p=1 / 2$ the inequality is equivalent to $\frac{5}{8} k \leq \rho$.
} 


\subsection{Comparison: joint liability versus individual liability}

The following table summarizes the total NPV when there are two borrowers (and $\psi$ is linear, $\underline{w}=0$ and $2 \rho \geq(1-p)(3-p) k)$ under the optimal rigid or discretionary contract ${ }^{40}$ depending on the form of the liability.

\begin{tabular}{|c|c|c|}
\hline Liability & The optimal rigid contract & The optimal discretionary contract \\
\hline Joint & $V-(1-p)^{2} 2(\psi(\rho)-\rho)$ & $V-(1-p)^{2} k$ \\
\hline Individual & $V-\left[(1-p)^{2}+p(1-p)\right] 2(\psi(\rho)-\rho)$ & $V-\left[(1-p)^{2}+2 p(1-p)\right] k$ \\
\hline
\end{tabular}

where $V \equiv 2 p Y_{S}-2 \rho$ represents the NPV when the supervisor is honest.

Conditional on that the lender uses the optimal rigid contract (or the optimal discretionary contract), the change from individual liability to joint liability increases the NPV, as suggested by Observation 1 at the beginning of Section 4 . In the case of the optimal rigid contract, joint liability provides a partial insurance in that when only one project succeeds, the borrower whose project failed does not pay anything (i.e. $r_{F S}=0$ ) while he has to pay $\rho$ under individual liability. This increase in the NPV from the partial insurance is equal to $2 p(1-p)(\psi(\rho)-\rho)$. In the case of the optimal discretionary contract, the introduction of joint liability does not affect any insurance provision since full insurance is provided regardless of the type of liability. However, it reduces the cost of audit: by making the borrowers' total repayment when both projects succeed equal to the payment when only one succeeds (i.e. $\Delta_{2}=0$ ), the lender needs to conduct audit only when both projects fail. By contrast, under individual liability, the lender should conduct audit whenever at least one project fails. The reduction in the audit cost is equal to $2 p(1-p) k$.

We also find that joint liability makes a discretionary contract more likely to be optimal since if a discretionary contract is optimal under individual liability (i.e. $(1+p) k<$ $2(\psi(\rho)-\rho)$ holds from proposition $5(\mathrm{ii}))$, then a discretionary contract is optimal under joint liability (i.e. $k<2(\psi(\rho)-\rho)$ holds from proposition $4($ ii $)$ ).

Summarizing, we have

Proposition 6 When there are two borrowers, suppose A1', $\underline{w}=0,(1-p)(3-p) k \leq 2 \rho$ and $\psi(r)=\theta r$ with $\theta>1$.

\footnotetext{
${ }^{40}$ We abuse a little bit the terminology by using the term "the optimal discretionary contract" in the following sense. Although the contract is the optimal one among all the discretionary contracts if it is better than the optimal rigid contract, it may not be optimal among discretionary contracts if it is worse than the optimal rigid contract.
} 
(i) When the supervisor is honest, joint liability does not affect the financing cost.

(ii) When the supervisor can misbehave, it is strictly optimal to introduce joint liability since it either reduces the financing cost or provides borrowers with more insurance.

(iii) A discretionary contract is more likely optimal under joint liability than under individual liability.

\subsection{Joint liability versus mutual insurance}

Up to now, we have not considered the possibility that two borrowers can sign a sidecontract between themselves. Actually, Laffont and N'Guessan (2000), Laffont (2003), Laffont and Rey (2003) and Rai and Sjöström (2004) consider side-contracting. In our model, if the lender uses individual liability, then the borrowers might have an interest to sign a side-contract to provide mutual insurance. More precisely, consider the following timing in which after accepting the lending contract and before the realization of the state of nature, the borrowers sign a binding side-contract which specifies a state-contingent side-payment between themselves. Since the lending contract and the agents are symmetric, a side-contract does not need to specify any side-payment when both projects succeed or both fail. ${ }^{41}$ Hence, a side-contract only specifies a monetary transfer $x$ that a borrower whose project succeeds makes to a borrower whose project fails such that the latter uses $x$ to make his repayment to the lender. Note first that given a grand-contract, side-contracting has no impact on the supervisor's incentive since it does not affect the borrowers' total payment schedule.

Consider first joint liability. Then, we can show in two steps that the optimal grandcontract without side-contracting that we characterized in proposition 4 is still the optimal contract even though the borrowers can sign a side-contract. First, we can prove that there is no loss of generality in restricting attention to the lending contracts which induce no side-contracting (i.e. $x=0$ ). This is what is called the collusion-proofness principle ${ }^{42}$ in the literature on mechanism design under collusion and this principle holds in our context for the following reason. Suppose that a grand-contract $G^{J}=\left\{r_{S S}, r_{S F}, r_{F S}, r_{F F}, w_{n}, q_{n}\right\}$ induces the borrowers to sign a side-contract specifying a side transfer $x^{*} \neq 0$ as their optimal response. Then, consider another grand-contract $G^{J \prime}$ which is identical to $G^{J}$ except that $r_{S F}^{\prime}=r_{S F}+x^{*}$ and $r_{F S}^{\prime}=r_{F S}-x^{*}$. If the lender proposes $G^{J \prime}$, it must

\footnotetext{
${ }^{41}$ Actually, if $\psi$ is strictly convex then a side payment in state $F F$ from a borrower to the other borrower reduces the borrowers' sum of payoffs.

${ }^{42}$ Tirole (1986) is the first who introduced the concept. For instance, Laffont and Martimort (2000) and Jeon and Menicuci (2005) use this principle to design the optimal mechanism under collusion.
} 
be optimal for the borrowers to sign a side-contract specifying zero side-transfer (i.e. it is optimal for them not to sign any side-contract). Otherwise, $x^{*}$ cannot be an optimal response to $G^{J}$ and we have a contradiction. The collusion-proofness principle implies that side-contracting simply adds additional constraints to the lender's optimization problem; hence, the lender cannot achieve a strictly better outcome with side-contracting than without it. Second, it is easy to see that when the lender uses the optimal grand-contract without side-contracting in proposition 4 , it is optimal for the borrowers not to sign any side-contract since the grand-contract provides full insurance $\left(r_{F S}=0\right)$ at the state in which only one project succeeds. Therefore, we can conclude that the optimal grandcontract without side-contracting in proposition 4 is optimal even when borrowers can sign a side-contract.

Consider now individual liability. First, we note that the outcomes that the lender can achieve under individual liability are a subset of the outcomes achievable under joint liability regardless of whether or not the borrowers can sign a side-contract. Therefore, the lender cannot obtain under individual liability an outcome superior to the best she can achieve under joint liability. Second, we can show that if side-contracting is possible, under individual liability, the lender can achieve the outcome of the optimal rigid contract under joint liability (see proposition 4(i)a) by offering $G^{I *}=\left\{r_{S}=r_{F}=\rho+\frac{w}{2}, w_{n}=\underline{w}, q_{n}=0\right\}$. Under $G^{I *}$, it is optimal for the borrowers to sign a side-contract specifying $x^{*}=\rho+\frac{w}{2}$ because it maximizes the borrowers' expected payoffs. Therefore, $G^{I *}$ induces the outcome of the optimal rigid contract under joint liability. Last, when there is individual liability, side-contracting does not allow the lender to achieve the outcome of the optimal discretionary contract under joint liability in proposition 4(i)b. The latter contract specifies a repayment schedule such that $2 r_{S S}=r_{S F}+r_{F S}>2 r_{F F}=0$. This kind of schedule cannot be obtained under individual liability because $r_{S S}=r_{S F}$ and $r_{F S}=r_{F F}$ must hold and side-contracting has no impact on the total repayment schedule. As the table in subsection 4.4 reveals, the consequence is a higher audit cost under individual liability. Summarizing, we have:

Proposition 7 When there are two borrowers and A1' is satisfied,

(i) Under joint liability, the optimal grand-contract is the same regardless of whether or not the borrowers can sign a side-contract and the possibility of side-contracting has no impact on their payoffs.

(ii) When the borrowers can sign a side-contract,

a. the borrowers' payoffs cannot be higher under individual liability than under joint liability. 
b. If a rigid contract is optimal under joint liability, the maximal payoffs under joint liability can be achieved under individual liability by a grand-contact which induces the borrowers to sign a suitable side-contract.

c. If a discretionary contract is optimal under joint liability, the borrowers' payoffs are strictly higher under joint liability than under individual liability.

Proposition 7(ii)b implies that conditional on that a rigid contract is optimal, our model does not necessarily predict that we should observe the use of joint liability. Actually, the Grameen bank seems to recently have discontinued its previous practice of joint liability. ${ }^{43}$

\section{Discussions}

Consider the case of a single borrower who can choose between two investment projects of different size, a small one and a large one. The small project is the one described in section 3. In the large project the borrower invests $a(>1)$ units of money and the investment generates the revenue $a Y_{S}$ with probability $p \in(0,1)$, the revenue zero with probability $1-p$. The cost of capital is $a \rho$ and, in order to use our result in proposition 2 (iii), we assume $\underline{w}=0$. When the supervisor is honest, choosing the large project is optimal if and only if $p Y_{S}-\rho$ is positive because there are constant returns to scale. In other words, as long as the small project has a positive NPV, it is optimal to choose the large one. However, when the supervisor can be dishonest, it can be optimal to choose the small project even though $p Y_{S}-\rho>0$. Conditional on choosing the large project, proposition 2(iii) proves that a rigid contract is optimal if and only if $k \geq \psi(a \rho)-a \rho$. Since this inequality implies $k>\psi(\rho)-\rho$, a rigid contract is optimal in the small project if it is optimal in the large project. When a rigid contract is optimal regardless of the size of the project, choosing the small project instead of the large one is optimal if and only if $(a-1) p\left(Y_{S}-\rho\right)<(1-p)[\psi(a \rho)-\psi(\rho)]$ and this inequality may hold even though $p Y_{S}>\rho$. Therefore, staff's incentive problem creates a bias in project selection toward projects of smaller scale.

Suppose now that the borrower can choose between two investment projects of different probability of success: each of them requires one unit of money to invest but has a different probability of success. A (relatively) safe project produces a return of $Y_{S}$ with

\footnotetext{
${ }^{43}$ See http://www.grameen-info.org/bank/GBGlance.htm. We asked them when and why they eliminated joint liability but got no response.
} 
probability $p$ and zero return with probability $1-p$. A risky project produces a return of $Y_{S}^{\prime}>Y_{S}$ with probability $p^{\prime}(<p)$ and zero return with probability $1-p^{\prime}$. We assume $p Y_{S}=p^{\prime} Y_{S}^{\prime}$. Therefore, when the supervisor is honest, the borrower is indifferent between the two projects. When the supervisor can misbehave and $\underline{w}=0$, from proposition 2(iii), the borrower's expected payoff conditional on choosing the safer project is $p Y_{S}-\rho-$ $(1-p) \min \{\psi(\rho)-\rho, k\}$, which is strictly larger than the expected payoff conditional on choosing the riskier project: $p^{\prime} Y_{S}^{\prime}-\rho-\left(1-p^{\prime}\right) \min \{\psi(\rho)-\rho, k\}$. Therefore, staff's incentive problem creates a bias in project selection toward safer projects.

In this paper, we considered a three-tier hierarchy for simplicity. However, when we add additional layers into the hierarchy, a rigid lending contract is more likely to be optimal than a discretionary contract. Actually, the hierarchy of the Grameen bank is composed of head office, zonal office, area office, branch office, center, group, member. As long as the total payment that each staff member at the bottom of the hierarchy should collect does not depend on the realized returns of his borrowers, no staff member at a higher level of hierarchy has any discretion. Therefore, when a rigid contract is used, adding layers of hierarchy in our setting involves no extra cost except the minimum wages paid to the staff. By contrast, when a discretionary lending contract is used, even though the staff at the bottom are induced to behave well through audit or incentive pays, the staff at a higher level have also discretion and the bank has to incur additional costs to discourage embezzlement.

In spite of the benefit of protecting borrowers from staff's potential misconduct, a rigid lending contract has the cost of providing poor insurance to them. In the Grameen bank, this problem is mitigated to some extent by the Group and Emergency funds. The Group fund is a collective saving from which villagers could borrow when they need a short-term loan. The Emergency fund is a reserve into which borrowers have to contribute a fee at the end of the year and has evolved into a form of life insurance. Even though making each borrower's payment responsive to his individual shock can be very costly, making it responsive to a publicly observable shock affecting a whole region such as natural catastrophes can be managed in a centralized way with little agency cost. Actually, the Grameen bank provides Disaster funds to areas affected by natural catastrophes.

Staff's career concern is an important factor affecting their behavior. We can incorporate it into our model in the following way. Suppose that the supervisor derives a rent $U>0$ from having a job in the Grameen bank. Then the incentive constraint $\left(I C_{S F}\right)$ in section 3 is written as follows:

$$
w_{S}+U \geq\left(1-q_{F}\right)\left(r_{S}-r_{F}+w_{F}+U\right)
$$


which is equivalent to

$$
w_{S} \geq\left(1-q_{F}\right)\left(r_{S}-r_{F}+w_{F}\right)-q_{F} U
$$

As $U$ increases, the probability of audit necessary to satisfy $\left(I C_{S F}\right)$ decreases. Therefore, a positive rent makes it easier to induce a staff member to behave well. In general, $U$ would depend on his expectation about how long his organization would survive and what kind of careers he could make in the organization. As long as a microfinancing organization continues to grow and to maintain its good reputation, its staff would attach a high rent to their jobs and this makes it easier to induce their good behavior.

In our model, the only discretion that a staff member can have is in terms of making a report about the realized returns. However, in reality, there are other sources of discretion. In particular, a staff member can exercise his discretion when deciding whether or not a villager is eligible for a loan or how much loan a member can obtain, etc. This might induce staff's misconduct. Therefore, even though fixed repayment schedules are used, some monitoring of the staff's actions should be made. In fact, according to Yunus, his bank could maintain excellence "only if its monitoring system can reach out to all the remote and dark corners of the system and keep them clean". (Bornstein, 1997, p. 171)

\section{Conclusion}

Our paper tried to answer the following challenging question: how could one make a large organization managing a lot of money, such as the Grameen bank, honest while corruption is a norm in the country? We addressed the question by focusing on the bank staff's incentive to embezzle borrowers' repayments and found the rigid repayment schedules which minimize (or eliminate) the staff's discretion as an optimal response. We also found that joint liability reduces borrowers' burden of respecting the rigid repayment schedules by providing them with partial insurance. However, the same insurance can be provided by borrowers themselves under individual liability since they have an incentive to sign a side-contract for mutual insurance. We also found that the staff's incentive problem creates biases in project selection toward projects of small scale and small risk.

Recently, Yunus (2002) announced in "Grameen Bank II" some changes in the payment mechanism. The changes are introduced to reduce the tension between a borrower and his staff member which arises under a rigid repayment schedule when the former has difficulty making his repayment due to bad shocks. Grameen Bank II introduces more flexibility into the system and hence gives more discretion to its staff: borrowers can 
reschedule repayments and both the loan duration and the size of weekly installment can be varied. Our paper explains borrowers' burden of respecting a rigid repayment schedule and suggests that increasing staff's discretion may end up hurting borrowers by increasing the scope for staff's misconduct.

\section{Appendix \\ Proof of Proposition 2}

(i) We have already proved Proposition 2(i)a-b in the text. We only need to verify that borrower's payoff is positive in the optimal grand contract. Since A1 implies that the payoff is positive in the best contract between the rigid contract and the discretionary contract with $\Delta=\Delta^{\max }$, the payoff is positive also in the optimal grand contract.

(ii) We have shown in the text that $\Delta^{* S} \in\left\{\max \{0, \bar{\Delta}\}, \Delta^{\max }\right\}$ and that the optimal lending contract is determined by comparing $p\left(Y_{S}-\rho-\underline{w}\right)-(1-p) \psi(\rho+\underline{w})$ with $p\left(Y_{S}-\Delta^{\max }\right)$. Hence, the rigid contract is optimal if and only if $p \Delta^{\max } \geq \rho+\underline{w}+(1-$ $p)[\psi(\rho+\underline{w})-\rho-\underline{w}]$; by recalling that $\Delta^{\max }$ satisfies $(2)$, we can write the condition as $\rho+\underline{w}+(1-p) \frac{\Delta}{\Delta+\underline{w}} k \geq \rho+\underline{w}+(1-p)[\psi(\rho+\underline{w})-\rho-\underline{w}]$, which is equivalent to (8).

(iii) It is obvious that if $\underline{w}=0$, then $\bar{q}(\Delta)=1$ for any $\Delta>0$ and thus $\Delta^{* S}=\Delta^{\max }$ because $f(\Delta)=p(1-p)\left\{\psi^{\prime}\left[r_{F}^{\text {stick }}(\Delta)\right]-1\right\}>0$ for any $\Delta \in\left[\bar{\Delta}, \Delta^{\text {max }}\right]$. The condition $k \geq \psi(\rho)-\rho$ comes from $(8)$ when $\underline{w}=0$.

\section{Proof of lemma 4}

(i) In $\left(L r^{J}\right)$, (i) $q_{2}$ appears only in the right hand side of (BE) and $q_{2}=0$ is the value which minimizes this right hand side; (ii) $w_{0}$ appears in the right hand side of (BE) and in (12), thus $\underline{w}$ - the smallest feasible value of $w_{0}$ - most relaxes these constraints.

(ii) We first show a general result, which is independent of the particular relaxed problem that is considered. Let $\Delta_{n \hat{n}} \equiv R(n)-R(\hat{n})$; then $\Delta_{\hat{n} n} \equiv-\Delta_{n \hat{n}}$ and $\mathrm{IC}_{n \hat{n}}$ and $\mathrm{IC}_{\hat{n} n}$ are expressed as $w_{n} \geq\left(1-q_{\hat{n}}\right)\left(\Delta_{n \hat{n}}+w_{\hat{n}}\right)$ and $w_{\hat{n}} \geq\left(1-q_{n}\right)\left(-\Delta_{n \hat{n}}+w_{n}\right)$, respectively. We show that if $\Delta_{n \hat{n}} \geq 0$ and $\mathrm{IC}_{n \hat{n}}$ is satisfied, then $\mathrm{IC}_{\hat{n} n}$ holds as well. This fact is obvious if $w_{n}=\underline{w}$. If instead $w_{n}=\left(1-q_{\hat{n}}\right)\left(\Delta_{n \hat{n}}+w_{\hat{n}}\right)$, then $\mathrm{IC}_{\hat{n} n}$ reduces to $w_{\hat{n}} \geq\left(1-q_{n}\right)\left[-q_{\hat{n}} \Delta_{n \hat{n}}+\left(1-q_{\hat{n}}\right) w_{\hat{n}}\right]$ and is satisfied.

This result proves that $\mathrm{IC}_{01}$ is satisfied in the solution to $\left(L r^{J}\right)$. Regarding $\mathrm{IC}_{02}$ and $\mathrm{IC}_{12}$, we need to distinguish four different cases depending on whether $\mathrm{IC}_{20}$ and/or $\mathrm{IC}_{21}$ bind. It is clear from the above result that $\mathrm{IC}_{02}$ and $\mathrm{IC}_{12}$ are satisfied if either $\mathrm{IC}_{20}$ and $\mathrm{IC}_{21}$ both bind or are both slack. If only $\mathrm{IC}_{20}$ binds, then we know that $\mathrm{IC}_{02}$ holds and $\mathrm{IC}_{12}$ reduces to $w_{1} \geq-q_{0} \Delta_{2}+\left(1-q_{0}\right)\left(\Delta_{1}+\underline{w}\right)$, which is weaker than $\mathrm{IC}_{10}$. If only $\mathrm{IC}_{21}$ binds, 
then $\mathrm{IC}_{12}$ is satisfied and $\mathrm{IC}_{02}$ reduces to $\underline{w} \geq-\Delta_{1}-q_{1} \Delta_{2}+\left(1-q_{1}\right) w_{1}$; this inequality holds in both in the case of $w_{1}=\underline{w}$ and in the case of $w_{1}=\left(1-q_{0}\right)\left(\Delta_{1}+\underline{w}\right)$.

\section{Proof of lemma 5}

We first prove that $\left(\mathrm{IC}_{21}\right)$ always binds. If $\left(\mathrm{IC}_{21}\right)$ is slack, then $q_{1}=0$ (otherwise it is profitable and feasible to reduce $q_{1}$ ) and $w_{2}>\Delta_{2}+w_{1}$ needs to hold. There are two cases to consider: when $\left(\mathrm{IC}_{20}\right)$ is slack and when $\left(\mathrm{IC}_{20}\right)$ binds. If $\left(\mathrm{IC}_{20}\right)$ is slack, then $w_{2}=\underline{w}$ and so $w_{2}>\Delta_{2}+w_{1}$ is violated. If $\left(\mathrm{IC}_{20}\right)$ binds, then $w_{2}=\left(1-q_{0}\right) \Delta_{2}+\left(1-q_{0}\right)\left(\Delta_{1}+\underline{w}\right)$ and again $w_{2}>\Delta_{2}+w_{1}$ fails to hold because $w_{1} \geq\left(1-q_{0}\right)\left(\Delta_{1}+\underline{w}\right)$.

Given that $\left(\mathrm{IC}_{21}\right)$ binds, now we prove that it never arises the case in which both $\left(\mathrm{IC}_{20}\right)$ and $\left(\mathrm{IC}_{10}\right)$ are slack. If this were the case, then $q_{0}=0$ and $w_{1}=\underline{w}$, since, otherwise, it is profitable and feasible to reduce $q_{0}$ and $w_{1}$. The inequality $\underline{w}>\Delta_{1}+\underline{w}$ would be equivalent to $\left(\mathrm{IC}_{10}\right)$ slack, but it fails to hold since $\Delta_{1} \geq 0$.

\section{Proof of lemma 6}

(i)a. From $\left(\mathrm{IC}_{21}\right)$ and $\left(\mathrm{IC}_{20}\right)$ binding and $\left(\mathrm{IC}_{10}\right)$ slack we obtain

$$
w_{1}=\underline{w}, \quad w_{2}=\left(1-q_{0}\right)\left(\Delta_{2}+\Delta_{1}+\underline{w}\right), \quad q_{1}=1-\frac{\left(1-q_{0}\right)\left(\Delta_{2}+\Delta_{1}+\underline{w}\right)}{\Delta_{2}+\underline{w}}
$$

Hence, $w_{2} \geq \underline{w}$ and $q_{1} \geq 0$ are equivalent to $q_{0} \in\left[\frac{\Delta_{1}}{\Delta_{2}+\Delta_{1}+\underline{w}}, \frac{\Delta_{2}+\Delta_{1}}{\Delta_{2}+\Delta_{1}+\underline{w}}\right]$ and $\left(\mathrm{IC}_{10}\right)$ slack reduces to $q_{0}>\frac{\Delta_{1}}{\Delta_{1}+\underline{w}}$. By plugging (21) into the objective function we find a linear function of $q_{0}$ which is minimized either at $q_{0}=\frac{\Delta_{1}}{\Delta_{2}+\Delta_{1}+\underline{w}}$ or at $q_{0}=\frac{\Delta_{2}+\Delta_{1}}{\Delta_{2}+\Delta_{1}+\underline{w}}$. In the second case, which implies $q_{1}=\frac{\Delta_{2}}{\Delta_{2}+\underline{w}}$ and $w_{2}=\underline{w}$, ( $\left(\overline{\mathrm{C}}_{10}\right)$ is slack and contract $\eta$ is obtained. In the first case, instead, $\left(\mathrm{IC}_{10}\right)$ is not slack.

(i)b. From $\left(\mathrm{IC}_{10}\right)$ and $\left(\mathrm{IC}_{21}\right)$ binding we find

$$
w_{1}=\left(1-q_{0}\right)\left(\Delta_{1}+\underline{w}\right) \quad \text { and } \quad w_{2}=\left(1-q_{1}\right)\left(\Delta_{2}+\left(1-q_{0}\right)\left(\Delta_{1}+\underline{w}\right)\right)
$$

Hence, $w_{1} \geq \underline{w}$ is equivalent to $q_{0} \leq \frac{\Delta_{1}}{\Delta_{1}+\underline{w}}$ and $w_{2} \geq \underline{w}$ is equivalent to

$$
\left(1-q_{1}\right)\left(\Delta_{2}+\left(1-q_{0}\right)\left(\Delta_{1}+\underline{w}\right)\right) \geq \underline{w}
$$

From (22) it follows that $\left(\mathrm{IC}_{20}\right)$ reduces to $q_{1} \leq f\left(q_{0}\right)$, where $f\left(q_{0}\right) \equiv q_{0} \frac{\Delta_{2}}{\Delta_{2}+\Delta_{1}+\underline{w}-q_{0}\left(\Delta_{1}+\underline{w}\right)}$ is an increasing and convex function such that $f(0)=0$ and $f\left(\frac{\Delta_{1}}{\Delta_{1}+\underline{w}}\right)=\frac{\Delta_{2} \Delta_{1}}{\left(\Delta_{2}+\underline{w}\right)\left(\Delta_{1}+\underline{w}\right)}$. The feasible set $F$ for $\left(q_{0}, q_{1}\right)$ is therefore $F=\left\{\left(q_{0}, q_{1}\right) \in \mathbb{R}_{+}^{2}: q_{0} \leq \frac{\Delta_{1}}{\Delta_{1}+\underline{w}}\right.$ and $\left.q_{1} \leq f\left(q_{0}\right)\right\}$ since $\left(\mathrm{IC}_{20}\right)$ is equivalent to $w_{2} \geq\left(1-q_{0}\right) \Delta_{2}+w_{1}$ and in any point of $\bar{F}$ (a) $\left(\mathrm{IC}_{20}\right)$ holds; 
(b) $w_{2} \geq\left(1-q_{0}\right) \Delta_{2}+w_{1} \geq \underline{w}$, thus (23) is satisfied. From (22) and (14) we derive the following objective function to minimize with respect to $\left(q_{0}, q_{1}\right) \in F$ :

$Q\left(q_{0}, q_{1}\right)=2 \rho+p^{2}\left(1-q_{1}\right)\left(\Delta_{2}+\left(1-q_{0}\right)\left(\Delta_{1}+\underline{w}\right)\right)+2 p(1-p)\left(\left(1-q_{0}\right)\left(\Delta_{1}+\underline{w}\right)+k q_{1}\right)+(1-p)^{2}\left(\underline{w}+k q_{0}\right)$

We now prove the statement in lemma 6(i)b. First notice that no point in the interior of $F$ minimizes $Q$ since the Hessian matrix of $Q$ is indefinite for any $\left(q_{0}, q_{1}\right)$ :

$$
\frac{\partial^{2} Q}{\partial q_{0}^{2}}=\frac{\partial^{2} Q}{\partial q_{1}^{2}}=0 \quad \frac{\partial^{2} Q}{\partial q_{0} \partial q_{1}}=p^{2}\left(\Delta_{1}+\underline{w}\right)>0
$$

This violates the second order condition for a minimum, which requires the Hessian matrix to be positive semi-definite.

We can neglect any point $\left(\widetilde{q_{0}}, 0\right)$ on the boundary of $F$ such that $0<\widetilde{q_{0}}<\frac{\Delta_{1}}{\Delta_{1}+\underline{w}}$ because $Q$ is linear in $q_{0}$ and this implies $\min \left\{Q(0,0), Q\left(\frac{\Delta_{1}}{\Delta_{1}+\underline{w}}, 0\right)\right\} \leq Q\left(\widetilde{q_{0}}, 0\right)$. Likewise, we can neglect any point $\left(\frac{\Delta_{1}}{\Delta_{1}+\underline{w}}, \widetilde{q_{1}}\right)$ on the boundary of $F$ such that $0<\widetilde{q_{1}}<f\left(\frac{\Delta_{1}}{\Delta_{1}+\underline{w}}\right)$ because $Q$ is linear in $q_{1}$. As a consequence, only $\left(\frac{\Delta_{1}}{\Delta_{1}+\underline{w}}, 0\right)$ may be a minimum point for $Q$ in the subset of $F$ in which $\left(\mathrm{IC}_{20}\right)$ is slack and at $\left(q_{0}, q_{1}\right)=\left(\frac{\Delta_{1}}{\Delta_{1}+\underline{w}}, 0\right)$ we find contract $\beta$.

(i)c. When all the three constraints bind we have $q_{1}=f\left(q_{0}\right)$ and $Q\left(q_{0}, q_{1}\right)$ is equal to

$$
\begin{aligned}
& \bar{Q}\left(q_{0}\right) \equiv Q\left(q_{0}, f\left(q_{0}\right)\right)=2 \rho+p^{2}\left(1-f\left(q_{0}\right)\right)\left(\Delta_{2}+\left(1-q_{0}\right)\left(\Delta_{1}+\underline{w}\right)\right) \\
& +2 p(1-p)\left(\left(1-q_{0}\right)\left(\Delta_{1}+\underline{w}\right)+k f\left(q_{0}\right)\right)+(1-p)^{2}\left(\underline{w}+k q_{0}\right) \\
= & 2 \rho+2 p(1-p) k f\left(q_{0}\right)+(1-p)^{2} k q_{0}+p\left(1-q_{0}\right)\left(p \Delta_{2}+(2-p)\left(\Delta_{1}+\underline{w}\right)\right)
\end{aligned}
$$

Since $f$ is convex, also $\bar{Q}$ is so. Hence, $\bar{Q}$ is minimized at $q_{0}=0$ if $\bar{Q}^{\prime}(0) \geq 0$ (contract $\alpha$ ), at $q_{0}=\frac{\Delta_{1}}{\Delta_{1}+\underline{w}}$ if $\bar{Q}^{\prime}\left(\frac{\Delta_{1}}{\Delta_{1}+\underline{w}}\right) \leq 0($ contract $\gamma)$, at $q_{0}^{*} \in\left(0, \frac{\Delta_{1}}{\Delta_{1}+\underline{w}}\right)$ if $\bar{Q}^{\prime}(0)<0<\bar{Q}^{\prime}\left(\frac{\Delta_{1}}{\Delta_{1}+\underline{w}}\right)$ $($ contract $\delta){ }^{44}$

(ii) Suppose that $\Delta_{2}>0=\Delta_{1}$. Then $w_{1}=\underline{w}$ since $\left(\mathrm{IC}_{10}\right)$ is $w_{1} \geq\left(1-q_{0}\right) \underline{w}$. Lemma 5 implies that $\left(\mathrm{IC}_{21}\right)$ binds and therefore $w_{2}=\left(1-q_{1}\right)\left(\Delta_{2}+\underline{w}\right) \cdot\left(\mathrm{IC}_{20}\right)$ reduces to $q_{0} \geq q_{1}$ and therefore we have $q_{0}=q_{1}$ because $q_{0}>q_{1}$ implies that both $\left(\mathrm{IC}_{10}\right)$ and $\left(\mathrm{IC}_{20}\right)$ are slack, violating lemma 5. Thus, $q_{1}=q_{0} \leq \frac{\Delta_{2}}{\Delta_{2}+\underline{w}}$ in order to satisfy $w_{2} \geq \underline{w}$. The objective function is then $2 \rho+p^{2}\left(1-q_{0}\right)\left(\Delta_{2}+\underline{w}\right)+2 p(1-p)\left(\underline{w}+k q_{0}\right)+(1-p)^{2}\left(\underline{w}+k q_{0}\right)$, which is linear with respect to $q_{0} \in\left[0, \frac{\Delta_{2}}{\Delta_{2}+\underline{w}}\right]$. Thus, the optimal $q_{0}$ is either 0 or $\frac{\Delta_{2}}{\Delta_{2}+\underline{w}}$ and contract $\alpha$ is obtained for $q_{0}=0$, contract $\eta$ for $q_{0}=\frac{\Delta_{2}}{\Delta_{2}+\underline{w}}$.

Suppose that $\Delta_{2}=\Delta_{1}=0$. Then all incentive constraints are satisfied with $w_{2}=w_{1}=\underline{w}$, $q_{1}=q_{0}=0$, which minimize the financing cost (as if the supervisor were honest). Contract $\alpha$ is obtained.

\footnotetext{
${ }^{44}$ Since $\bar{Q}^{\prime}(x)=\frac{2 p(1-p) k \Delta_{2}\left(\Delta_{2}+\Delta_{1}+\underline{w}\right)}{\left(\Delta_{2}+(1-x)\left(\Delta_{1}+\underline{w}\right)\right)^{2}}+(1-p)^{2} k-p\left(p \Delta_{2}+(2-p)\left(\Delta_{1}+\underline{w}\right)\right)$, the condition $\bar{Q}^{\prime}(0)<$ $0<\bar{Q}^{\prime}\left(\frac{\Delta_{1}}{\Delta_{1}+\underline{w}}\right)$ is equivalent to the condition mentioned in footnote 35 .
} 
Suppose that $\Delta_{2}=0<\Delta_{1}$. Then, $\left(\mathrm{IC}_{21}\right)$ is redundant because $\left(\mathrm{IC}_{20}\right)$ and $\left(\mathrm{IC}_{10}\right)$ jointly imply that $\left(\mathrm{IC}_{21}\right)$ is satisfied; hence, $q_{1}=0$. Notice that $\left(\mathrm{IC}_{20}\right)$ and $\left(\mathrm{IC}_{10}\right)$ reduce to $w_{1} \geq\left(1-q_{0}\right)\left(\Delta_{1}+\underline{w}\right)$ and $w_{2} \geq\left(1-q_{0}\right)\left(\Delta_{1}+\underline{w}\right)$, respectively, and either they both bind or are both slack. But by Lemma 5 both bind. We plug $w_{2}=w_{1}=\left(1-q_{0}\right)\left(\Delta_{1}+\underline{w}\right)$ into (9), with $q_{0} \in\left[0, \frac{\Delta_{1}}{\Delta_{1}+\underline{w}}\right]$. Since the objective function is linear in $q_{0}$, we find either contract $\alpha$ or $\beta$.

\section{Proof of lemma 7}

In this proof we suppose that $Y_{S}$ is sufficiently large so that lemma 3 applies. Suppose that $G=\left(R(0), R(1), R(2), w_{0}, w_{1}, w_{2}, q_{0}, q_{1}, q_{2}\right)$ is such that $\Delta_{2}>0$. We find $G^{\prime}$ which is weakly better than $G$ and satisfies $\Delta_{2}^{\prime}<\Delta_{2}$. Precisely, $R^{\prime}(1)=R(1)+\frac{p}{2-p} \varepsilon, R^{\prime}(2)=$ $R(2)-\frac{2(1-p)}{2-p} \varepsilon, R^{\prime}(0)=R(0)$ for a small $\varepsilon>0$ and $q_{n}^{\prime}=q_{n}$ for $n=0,1,2$. In $G^{\prime}$, the borrowers' payoff and expected payment are unchanged and $\Delta_{2}^{\prime}=\Delta_{2}-\varepsilon, \Delta_{1}^{\prime}=\Delta_{1}+\frac{p}{2-p} \varepsilon$ and $\Delta_{2}^{\prime}+\Delta_{1}^{\prime}=\Delta_{2}+\Delta_{1}-\frac{2(1-p)}{2-p} \varepsilon$. We now determine wages $w_{2}^{\prime}, w_{1}^{\prime}, w_{0}^{\prime}$ such that $G^{\prime}$ satisfies $(\mathrm{BE})$, and thus it is feasible, and yields the expected wage bill that is weakly smaller than the one under $G .^{45}$ By lemma 6 , we need to distinguish three different cases depending on whether the binding constraints in (12) are (i) $\mathrm{IC}_{20}$ and $\mathrm{IC}_{21}$; (ii) $\mathrm{IC}_{10}$ and $\mathrm{IC}_{21}$; (iii) $\mathrm{IC}_{21}, \mathrm{IC}_{20}$ and $\mathrm{IC}_{10}$. In case (i), both $\mathrm{IC}_{20}$ and $\mathrm{IC}_{21}$ are relaxed in $G^{\prime}$ with respect to $G$, thus we can choose $w_{2}^{\prime}=w_{2}, w_{1}^{\prime}=w_{1}, w_{0}^{\prime}=w_{0}$. In case (ii) we set $w_{1}^{\prime}=w_{1}+\left(1-q_{0}\right) \frac{p}{2-p} \varepsilon$ and $w_{2}^{\prime}=w_{2}+\left(1-q_{1}\right)\left[-\varepsilon+\left(1-q_{0}\right) \frac{p}{2-p} \varepsilon\right]$, thus the change in the expected wage paid to the supervisor is

$$
2 p(1-p)\left(1-q_{0}\right) \frac{p}{2-p} \varepsilon+p^{2}\left(1-q_{1}\right)\left[-\varepsilon+\left(1-q_{0}\right) \frac{p}{2-p} \varepsilon\right]
$$

In order to show that (24) is negative, notice that from $\mathrm{IC}_{21}$ binding and $\mathrm{IC}_{20}$ slack it follows that $\left(1-q_{1}\right)\left(\Delta_{2}+w_{1}\right)>\left(1-q_{0}\right)\left(\Delta_{2}+\Delta_{1}+\underline{w}\right)$ and then $1-q_{1}>1-q_{0}$. Thus, $(24)$ is smaller than $2 p(1-p)\left(1-q_{0}\right) \frac{p}{2-p} \varepsilon+p^{2}\left(1-q_{0}\right)\left[-\varepsilon+\left(1-q_{0}\right) \frac{p}{2-p} \varepsilon\right]=-\frac{p^{3}\left(1-q_{0}\right) q_{0}}{2-p} \varepsilon \leq 0$. In case (iii), we pick $w_{1}^{\prime}=w_{1}+\left(1-q_{0}\right) \frac{p}{2-p} \varepsilon$ and $w_{2}^{\prime}=w_{2}-\left(1-q_{0}\right) \frac{2(1-p)}{2-p} \varepsilon$ because the right hand side of $\mathrm{IC}_{20}$ decreases by $\left(1-q_{0}\right) \frac{2(1-p)}{2-p} \varepsilon$ while the right hand side of $\mathrm{IC}_{21}$ decreases by $\left(1-q_{1}\right)\left[\varepsilon-\left(1-q_{0}\right) \frac{p}{2-p} \varepsilon\right]$ and $1-q_{1}>1-q_{0}$ implies $\left(1-q_{0}\right) \frac{2(1-p)}{2-p} \varepsilon \leq\left(1-q_{1}\right)\left[\varepsilon-\left(1-q_{0}\right) \frac{p}{2-p} \varepsilon\right]$. The change in the expected wage bill is $2 p(1-p)\left(1-q_{0}\right) \frac{p}{2-p} \varepsilon-p^{2}\left(1-q_{0}\right) \frac{2(1-p)}{2-p} \varepsilon=0$.

In this way we have proved that whenever a lending contract is such that $\Delta_{2}>0$, we can find another contract which is at least as good and has a smaller $\Delta_{2}$. Ultimately, this

\footnotetext{
${ }^{45}$ In some cases the expected wage bill is strictly smaller than the one under $G$. Then, it is possible to strictly increase the borrowers' payoff by reducing $R^{\prime}(2), R^{\prime}(1)$ and $R^{\prime}(0)$ by a same amount.
} 
allows to look for the optimal contract within the set of contracts which satisfy $\Delta_{20}=0$. When $\Delta_{2}=0$, lemma 6 (ii) establishes that the optimal supervisory contract belongs to $\{\alpha, \beta, \eta\}$. However, it is straightforward to see that $\beta=\eta$ if $\Delta_{2}=0$ and so we restrict our attention to $\{\alpha, \beta\}$.

\section{Proof of Proposition 4}

(i) The proof of Proposition 4(i)a-b appears in the text. In order to verify that the borrowers' payoff is positive in the optimal grand contract, notice that the payoff under the rigid contract described in (i)a is $2 p Y_{S}-p(2-p)(2 \rho+\underline{w})-(1-p)^{2} 2 \psi\left(\rho+\frac{1}{2} \underline{w}\right)=$ $2 p Y_{S}-(2 \rho+\underline{w})-(1-p)^{2}\left(2 \psi\left(\rho+\frac{1}{2} \underline{w}\right)-2 \rho-\underline{w}\right)$ and it is obvious that assumption A1'(i) implies that this payoff is positive. The payoff in the optimal discretionary contract is $2 p Y_{S}-p(2-p)\left[2 r_{F F}\left(\Delta_{1}^{* \beta}\right)+\Delta_{1}^{* \beta}\right]-(1-p)^{2} 2 \psi\left(\Delta_{1}^{* \beta}\right)$, which is at least as large as $2 p Y_{S}-p(2-p)\left[2 r_{F F}\left(\Delta_{1}^{\max }\right)+\Delta_{1}^{\max }\right]-(1-p)^{2} 2 \psi\left(\Delta_{1}^{\max }\right)$ by definition of $\Delta_{1}^{* \beta}$. Furthermore, $2 p Y_{S}-p(2-p)\left[2 r_{F F}\left(\Delta_{1}^{\max }\right)+\Delta_{1}^{\max }\right]-(1-p)^{2} 2 \psi\left(\Delta_{1}^{\max }\right)=2 p Y_{S}-p(2-p) \Delta_{1}^{\max }=$ $2 p Y_{S}-C_{\beta}^{J}\left(\Delta_{1}^{\max }, 0\right)$ (by definition of $\Delta_{1}^{\max }$ ) and $C_{\beta}^{J}\left(\Delta_{1}, 0\right)=2 \rho+\underline{w}+(1-p)^{2} k \frac{\Delta_{1}}{\Delta_{1}+\underline{w}}<$ $2 \rho+\underline{w}+(1-p)^{2} k$; thus, A1'(i) implies $2 p Y_{S}-C_{\beta}^{J}\left(\Delta_{1}^{\max }, 0\right)>0 .{ }^{46}$

Finally, the condition $R(1) \leq Y_{S}$ is satisfied by the optimal rigid contract since then $R(1)=2 \rho+\underline{w}$ while A1'(ii) requires that $Y_{S} \geq \Delta_{1}^{\max }$ and (9) implies $\Delta_{1}^{\max }>2 \rho+\underline{w}$. In the optimal discretionary contract we have $R(1)=2 r_{F F}\left(\Delta_{1}^{* \beta}\right)+\Delta_{1}^{* \beta}=2 \rho+\underline{w}+(1-$ $p)^{2} k \bar{q}\left(\Delta_{1}^{* \beta}\right)+(1-p)^{2} \Delta_{1}^{* \beta}$ and the function $2 \rho+\underline{w}+(1-p)^{2} k \bar{q}\left(\Delta_{1}\right)+(1-p)^{2} \Delta_{1}$ is monotone and increasing with respect to $\Delta_{1}$. Thus it achieves its maximum at $\Delta_{1}=\Delta_{1}^{\max }$, where it takes the value $2 r_{F F}\left(\Delta_{1}^{\max }\right)+\Delta_{1}^{\max }=\Delta_{1}^{\max }$; this is not larger than $Y_{S}$ because of A1'(ii).

(ii) The proof that $\Delta_{1}^{* \beta} \in\left\{\max \left\{0, \bar{\Delta}_{1}\right\}, \Delta_{1}^{\max }\right\}$ is straightforward since it follows from the convexity of $(18)$ over the interval $\left[\max \left\{0, \bar{\Delta}_{1}\right\}, \Delta_{1}^{\max }\right]$. As in the case of proposition 2(ii), we know that if $\Delta_{1}^{* \beta}=\bar{\Delta}_{1}$ then the optimal grand contract is such that $\Delta_{1}=0$ and thus we just need to compare the payoff at $\Delta_{1}=0$ with the payoff at $\Delta_{1}=\Delta_{1}^{\max }$. By using (9) we find that the former payoff is larger than the latter if and only if $k \bar{q}\left(\Delta_{1}\right) \geq$ $2\left[\psi\left(\rho+\frac{1}{2} \underline{w}\right)-\rho-\frac{1}{2} \underline{w}\right]$.

(iii) The proof is very similar to the proof of Proposition 2(iii) and thus is omitted.

\section{Proof of lemma 8}

\footnotetext{
${ }^{46}$ Notice that A1' is more restrictive than needed for the case of joint liability because we want the same assumption to cover the case of individual liability as well, in which the borrowers' payoff is smaller than the one under joint liability (this fact is explained in detail in subsection 4.4).
} 
We consider all the possible cases in which $\Delta_{1}<0$ and/or $\Delta_{2}<0$ and in any such case we prove that it is possible to (weakly) increase the borrowers' payoff by satisfying $\Delta_{1} \geq 0$ and $\Delta_{2} \geq 0$. In particular, we need to consider four different regimes.

1. $R(0) \geq \max \{R(1), R(2)\}$ (regime $\mathrm{B}$ )

Let $G^{B}$ denote the best grand contract within the set of grand contracts satisfying $R(0) \geq$ $R(1)$ and $R(0) \geq R(2)$. We show that $G^{B}=G^{\prime}$, with $R^{\prime}(0)=R^{\prime}(1)=R^{\prime}(2)=2 \rho+\underline{w}$ and $w_{0}^{\prime}=w_{1}^{\prime}=w_{2}^{\prime}=\underline{w}, q_{0}^{\prime}=q_{1}^{\prime}=q_{2}^{\prime}=0$; thus, $G^{B}$ satisfies $\Delta_{1} \geq 0$ and $\Delta_{2} \geq 0$. It is easy to see that $G^{\prime}$ is feasible because it satisfies (10) and (BE). The borrowers' payoff in $G^{\prime}$ is $2 p Y_{S}-p^{2} R^{\prime}(2)-2 p(1-p) R^{\prime}(1)-(1-p)^{2} \psi\left(\frac{R^{\prime}(0)}{2}\right)$ because A1'(ii) implies that $Y_{S}>$ $R^{\prime}(1)=2 \rho+\underline{w}$ and thus lemma 3 applies. The borrowers' payoff with a grand contract $G$ such that $R(0)>\max \{R(1), R(2)\}$ or $R(0)=\max \{R(1), R(2)\}>\min \{R(1), R(2)\}$ is smaller than the one with $G^{\prime}$ because of the following argument. First, suppose for the moment that the expected payment is the same in $G$ as in $G^{\prime}$. Then $G^{\prime}$ is better than $G$ because of lemma 1 , given that $R^{\prime}(0)=R^{\prime}(1)=R^{\prime}(2)$ implies $R(0)>R^{\prime}(0)$. Second, the expected payment in $G$ is actually larger than in $G^{\prime}$ because $R(0)=R(1)=R(2)$ fails to hold and thus some cost must be borne to discourage embezzlement. Third, while $Y_{S} \geq R^{\prime}(1)$ holds, it is possible to have $Y_{S}<R(1)$ and in this case the borrowers face some cost from reducing consumption in states $S F$ and $F S$ and not only in state $F F$.

2. $R(2) \geq R(0) \geq R(1)$ (regime $C$ )

We show that within the set of grand contracts satisfying $R(2) \geq R(0) \geq R(1)$, the best contract $G^{C}$ is such that $R^{C}(0)=R^{C}(1)$ and therefore $\Delta_{1} \geq 0$ and $\Delta_{2} \geq 0$ are satisfied. Let $\Delta_{20} \equiv R(2)-R(0) \geq 0$ and $\Delta_{01} \equiv R(0)-R(1) \geq 0$. We study the following reduced program in which we consider only $\mathrm{IC}_{21}, \mathrm{IC}_{20}$ and $\mathrm{IC}_{01}$ among the incentive constraints.

$$
\begin{array}{cl}
\mathrm{IC}_{21} & w_{2} \geq\left(1-q_{1}\right)\left(\Delta_{20}+\Delta_{01}+w_{1}\right) \\
\mathrm{IC}_{20} & w_{2} \geq\left(1-q_{0}\right)\left(\Delta_{20}+w_{0}\right) \\
\mathrm{IC}_{01} & w_{0} \geq\left(1-q_{1}\right)\left(\Delta_{01}+w_{1}\right)
\end{array}
$$

A result analogous to lemma 4 holds and establishes that the solution to the relaxed problem is $G^{C}$ because it satisfies $\mathrm{IC}_{12}, \mathrm{IC}_{02}$ and $\mathrm{IC}_{10}$. We prove that $G^{C}$ is such that $\Delta_{01}^{C}=0$ by showing that starting from any contract $G$ satisfying $\Delta_{01}>0$, we can find $G^{\prime}$ which is better than $G$ and satisfies $\Delta_{01}^{\prime}=0$. Precisely, let $w_{n}^{\prime}=w_{n}, q_{n}^{\prime}=q_{n}$ for $n=0,1,2$ and $R^{\prime}(1)=R(1)+\left[p^{2}+(1-p)^{2}\right] \Delta_{01}, R^{\prime}(2)=R(2)-2 p(1-p) \Delta_{01}, R^{\prime}(0)=$ $R(0)-2 p(1-p) \Delta_{01}$; then $\Delta_{01}^{\prime}=0<\Delta_{01}$ and $\Delta_{20}^{\prime}=\Delta_{20}$. As a consequence, the incentive constraints are weakly relaxed and the borrowers' expected payment is unchanged; thus, $G^{\prime}$ satisfies $(\mathrm{BE})$. Furthermore, $R^{\prime}(1)>R(1)$ and $R^{\prime}(0)<R(0)$. By lemmas 1 and 3 , this 
fact implies that the borrowers' payoff is higher in $G^{\prime}$ than in $G$ as long as $Y_{S} \geq R^{\prime}(1)$. This proves that $G^{C}$ is such that $\Delta_{01}^{C}=0$ as long as $R^{C}(1) \leq Y_{S}$. Now we show that $R^{C}(1) \leq Y_{S}$ holds by finding $G^{C}$ under the assumption that $Y_{S}$ is large enough and then verifying that this assumption holds under $A 1^{\prime}$ (ii). When $\Delta_{01}=0$ and $\Delta_{20} \geq 0$, it is optimal to set (i) $w_{1}=w_{0}=\underline{w}$ because the right hand side of $\mathrm{IC}_{01}$ is not larger than $\underline{w}$; (ii) $q_{1}=q_{0}=q$ because if $q_{1}>q_{0}$ (for instance), then it is profitable to reduce $q_{1}$ slightly. Furthermore, $\mathrm{IC}_{21}$ is equivalent to $\mathrm{IC}_{20}$ and it binds since otherwise it is profitable to reduce $q$ (notice that for values of $q$ close to 0 , the right hand side of $\mathrm{IC}_{21}$ is larger than $\underline{w})$; this implies $q \in\left[0, \frac{\Delta_{20}}{\Delta_{20}+\underline{w}}\right]$. From (BE) binding we find $R(1)+p^{2} \Delta_{20}=$ $2 \rho+\underline{w}+p^{2} \Delta_{20}+q\left[k\left(1-p^{2}\right)-p^{2}\left(\Delta_{20}+\underline{w}\right)\right]$, where the right hand side is the financing cost. It is clear that this cost is minimized with respect to $q$ at $q=0$ if $\left(1-p^{2}\right) k-p^{2}\left(\Delta_{20}+\underline{w}\right) \geq 0$, at $q=\frac{\Delta_{20}}{\Delta_{20}+\underline{w}}$ otherwise. In any case, we have $R(1) \leq 2 \rho+\underline{w}$ and we know that $2 \rho+\underline{w}$ is smaller than $Y_{S}$ under A1'(ii).

\section{3. $R(1) \geq R(2) \geq R(0)$ (regime $D$ ).}

We show that within the set of grand contracts satisfying $R(1) \geq R(2) \geq R(0)$, the best contract $G^{D}$ is such that $R^{D}(1)=R^{D}(2)$, and therefore it satisfies $\Delta_{1} \geq 0$ and $\Delta_{2} \geq 0$. Let $\Delta_{12} \equiv R(1)-R(2) \geq 0$ and $\Delta_{20} \equiv R(2)-R(0) \geq 0$. We study a reduced program in which we consider only $\mathrm{IC}_{12}, \mathrm{IC}_{10}$ and $\mathrm{IC}_{20}$ among the incentive constraints:

$$
\left\{\begin{array}{c}
\mathrm{IC}_{12} \quad w_{1} \geq\left(1-q_{2}\right)\left(\Delta_{12}+w_{2}\right) \\
\mathrm{IC}_{10} \quad w_{1} \geq\left(1-q_{0}\right)\left(\Delta_{12}+\Delta_{20}+w_{0}\right) \\
\mathrm{IC}_{20} \quad w_{2} \geq\left(1-q_{0}\right)\left(\Delta_{20}+w_{0}\right)
\end{array}\right.
$$

A result analogous to lemma 4 holds and establishes that the solution to this relaxed problem satisfies $\mathrm{IC}_{21}, \mathrm{IC}_{01}$ and $\mathrm{IC}_{02}$. Suppose that $G$ is such that $\Delta_{12}>0$. We find $G^{\prime}$ which is weakly better than $G$ and satisfies $\Delta_{12}^{\prime}<\Delta_{12}$. Let $R^{\prime}(2)=R(2)+\frac{2(1-p)}{2-p} \varepsilon$, $R^{\prime}(1)=R(1)-\frac{p}{2-p} \varepsilon$ and $R^{\prime}(0)=R(0)$ with $\varepsilon>0$ and small; $q_{i}^{\prime}=q_{i}$ for $i=0,1,2$. Hence, $\Delta_{12}^{\prime}=\Delta_{12}-\varepsilon, \Delta_{20}^{\prime}=\Delta_{20}+\frac{2(1-p)}{2-p} \varepsilon$ and $\Delta_{12}^{\prime}+\Delta_{20}^{\prime}=\Delta_{12}+\Delta_{20}-\frac{p}{2-p} \varepsilon$. In $G^{\prime}$, the borrowers' expected payment is the same as in $G$ and their expected payoff is at least as large as in $G$, since $R^{\prime}(1)<R(1)$. We now determine $w_{i}^{\prime}, i=0,1,2$, such that $G^{\prime}$ satisfies $(25)$ and $(\mathrm{BE})$. This makes $G^{\prime}$ feasible and proves that within regime $D$, we can restrict our attention to contracts such that $\Delta_{12}=0$, without loss of generality.

A result similar to lemma 5 holds and implies that we must distinguish three different cases, depending on the binding constraints in (25): (i) $\mathrm{IC}_{12}, \mathrm{IC}_{10}$; (ii) $\mathrm{IC}_{12}, \mathrm{IC}_{20}$; (iii) $\mathrm{IC}_{12}, \mathrm{IC}_{10}, \mathrm{IC}_{20}$. In case (i), both $\mathrm{IC}_{12}$ and $\mathrm{IC}_{10}$ are relaxed in $G^{\prime}$ with respect to $G$, thus we can pick $w_{2}^{\prime}=w_{2}, w_{1}^{\prime}=w_{1}, w_{0}^{\prime}=w_{0}$. In case (ii) we set $w_{2}^{\prime}=w_{2}+\left(1-q_{0}\right) \frac{2(1-p)}{2-p} \varepsilon$ and 
$w_{1}^{\prime}=w_{1}+\left(1-q_{2}\right)\left[-\varepsilon+\left(1-q_{0}\right) \frac{2(1-p)}{2-p} \varepsilon\right]$, thus the change in the expected wage paid to the supervisor is

$$
2 p(1-p)\left(1-q_{2}\right)\left[-\varepsilon+\left(1-q_{0}\right) \frac{2(1-p)}{2-p} \varepsilon\right]+p^{2}\left(1-q_{0}\right) \frac{2(1-p)}{2-p} \varepsilon
$$

In order to show that (26) is negative, notice that from $\mathrm{IC}_{12}$ binding and $\mathrm{IC}_{10}$ slack it follows that $\left(1-q_{2}\right)\left[\Delta_{12}+\left(1-q_{0}\right)\left(\Delta_{20}+\underline{w}\right)\right]>\left(1-q_{0}\right)\left(\Delta_{12}+\Delta_{20}+\underline{w}\right)$ and then $1-q_{2}>1-q_{0}$. Thus, $(26)$ is smaller than $2 p(1-p)\left(1-q_{0}\right)\left[-\varepsilon+\left(1-q_{0}\right) \frac{2(1-p)}{2-p} \varepsilon\right]+p^{2}(1-$ $\left.q_{0}\right) \frac{2(1-p)}{2-p} \varepsilon=-\frac{4 p(1-p)^{2}\left(1-q_{0}\right) q_{0}}{2-p} \varepsilon \leq 0$. In case (iii), we choose $w_{2}^{\prime}=w_{2}+\left(1-q_{0}\right) \frac{2(1-p)}{2-p} \varepsilon$ and $w_{1}^{\prime}=w_{1}-\left(1-q_{0}\right) \frac{p}{2-p} \varepsilon$ because the right hand side of $\mathrm{IC}_{10}$ decreases by $\left(1-q_{0}\right) \frac{p}{2-p} \varepsilon$ while the right hand side of $\mathrm{IC}_{12}$ varies by $\left(1-q_{2}\right)\left[-\varepsilon+\left(1-q_{0}\right) \frac{2(1-p)}{2-p} \varepsilon\right]$. Given that $1-q_{2} \geq 1-q_{0}$, we see that $\left(1-q_{0}\right) \frac{p}{2-p} \varepsilon \leq\left(1-q_{2}\right)\left[\varepsilon-\left(1-q_{0}\right) \frac{2(1-p)}{2-p} \varepsilon\right]$. In this case, the change in the expected wage bill is $-2 p(1-p)\left(1-q_{0}\right) \frac{p}{2-p} \varepsilon+p^{2}\left(1-q_{0}\right) \frac{2(1-p)}{2-p} \varepsilon=0$.

In this way we have proved that whenever the lending contract is such that $\Delta_{12}>0$, there exists another contract which is at least as good and has a smaller $\Delta_{12}$. Therefore, in regime $\mathrm{D}$ we can consider only the contracts such that $\Delta_{12}=0$.

4. $R(1) \geq R(0) \geq R(2)$ (regime $E$ )

We show that within the set of grand contracts such that $R(1) \geq R(0) \geq R(2)$ the best contract $G^{E}$ is such that $R^{E}(0)=R^{E}(2)$; therefore, it belongs to regime $D$. Let $\Delta_{10} \equiv R(1)-R(0) \geq 0$ and $\Delta_{02} \equiv R(0)-R(2) \geq 0$. We study the reduced program in which we consider only $\mathrm{IC}_{10}, \mathrm{IC}_{12}$ and $\mathrm{IC}_{02}$ among the incentive constraints.

$$
\begin{array}{cl}
\mathrm{IC}_{10} & w_{1} \geq\left(1-q_{0}\right)\left(\Delta_{10}+w_{0}\right) \\
\mathrm{IC}_{12} & w_{1} \geq\left(1-q_{2}\right)\left(\Delta_{10}+\Delta_{02}+w_{2}\right) \\
\mathrm{IC}_{02} & w_{0} \geq\left(1-q_{2}\right)\left(\Delta_{02}+w_{2}\right)
\end{array}
$$

A result analogous to lemma 4 shows that the solution to this relaxed problem is $G^{E}$ because it satisfies $\mathrm{IC}_{01}, \mathrm{IC}_{21}$ and $\mathrm{IC}_{20}$. Suppose that $G$ is such that $\Delta_{02}>0$. We find $G^{\prime}$ which is better than $G$ and satisfies $\Delta_{02}^{\prime}=0$. Precisely, let $w_{n}^{\prime}=w_{n}, q_{n}^{\prime}=q_{n}$ for $n=0,1,2$ and $R^{\prime}(2)=R(2)+\left(1-p^{2}\right) \Delta_{02}, R^{\prime}(1)=R(1)-p^{2} \Delta_{02}, R^{\prime}(0)=R(0)-p^{2} \Delta_{02}$; then $\Delta_{02}^{\prime}=0<\Delta_{02}$ and $\Delta_{10}^{\prime}=\Delta_{10}$. As a consequence, the incentive constraints are weakly relaxed while the borrowers' expected payment is unchanged. Further, $R^{\prime}(1)<R(1)$ and $R^{\prime}(0)<R(0)$ and thus, by lemma 1 , the borrowers' payoff is larger in $G^{\prime}$ than in $G$. This proves that $G^{E}$ satisfies $\Delta_{02}=0$.

\section{Proof of Lemma 9}


(i) In contract $\delta, q_{0}^{*}$ is such that $\bar{Q}^{\prime}\left(q_{0}^{*}\right)=0$ and this condition is equivalent to $\frac{\partial Q\left[q_{0}^{*}, f\left(q_{0}^{*}\right)\right]}{\partial q_{0}}+\frac{\partial Q\left[q_{0}^{*}, f\left(q_{0}^{*}\right)\right]}{\partial q_{1}} f^{\prime}\left(q_{0}^{*}\right)=0$ (see the proof of lemma $6(\mathrm{i}) \mathrm{c}$ ). Since $f^{\prime}\left(q_{0}^{*}\right)>0$, it must be the case that $\frac{\partial Q\left[q_{0}^{*}, f\left(q_{0}^{*}\right)\right]}{\partial q_{0}}<0$ and $\frac{\partial Q\left[q_{0}^{*}, f\left(q_{0}^{*}\right)\right]}{\partial q_{1}}>0$, or $\frac{\partial Q\left[q_{0}^{*}, f\left(q_{0}^{*}\right)\right]}{\partial q_{0}} \geq 0$ and $\frac{\partial Q\left(q_{0}^{*}, f\left(q_{0}^{*}\right)\right]}{\partial q_{1}} \leq 0$. In the first case, $\delta$ is not an optimal supervisory contract because it is possible to reduce the cost by slightly increasing $q_{0}$ above $q_{0}^{*}$ and/or by slightly decreasing $q_{1}$ below $q_{1}^{*}=f\left(q_{0}^{*}\right)$. The proof is completed by showing that the second case cannot arise. Indeed, still using the proof of lemma $6(\mathrm{i}) \mathrm{c}$, we find

$$
\begin{aligned}
& \frac{\partial Q}{\partial q_{0}}=-p^{2}\left(1-q_{1}\right)(\Delta+\underline{w})-2 p(1-p)(\Delta+\underline{w})+(1-p)^{2} k \\
& \frac{\partial Q}{\partial q_{1}}=-p^{2}\left(\Delta+\left(1-q_{0}\right)(\Delta+\underline{w})\right)+2 p(1-p) k
\end{aligned}
$$

Then $\frac{\partial Q}{\partial q_{1}} \leq 0$ is equivalent to $k \leq \frac{p\left[\Delta+\left(1-q_{0}\right)(\Delta+\underline{w})\right]}{2(1-p)}$ and this inequality implies $\frac{\partial Q}{\partial q_{0}} \leq$ $-p^{2}\left(1-q_{1}\right)(\Delta+\underline{w})-2 p(1-p)(\Delta+\underline{w})+\frac{(1-p)}{2} p\left[\Delta+\left(1-q_{0}\right)(\Delta+\underline{w})\right]$. The right hand side of the last inequality is smaller than $-\frac{1}{2} p(1-p)(2 \Delta+3 \underline{w})<0$ for any $\left(q_{0}, q_{1}\right) \in[0,1]^{2}$.

(ii) It is easy to see that $C_{\alpha}^{I}, C_{\beta}^{I}$ and $C_{\eta}^{I}$ are concave. If also $C_{\gamma}^{I}$ is concave, then the concavity of $C^{I}(\Delta)=\min \left\{C_{\alpha}^{I}(\Delta), C_{\beta}^{I}(\Delta), C_{\gamma}^{I}(\Delta), C_{\eta}^{I}(\Delta)\right\}$ follows from Theorem $5.5 \mathrm{in}$ Rockafellar (1997). After some manipulations, we find that

$$
\frac{d^{2} C_{\gamma}^{I}}{d \Delta^{2}}=\frac{2 \underline{w}}{(\Delta+\underline{w})^{4}}\left\{\left[k(3 p-1)(1-p)-p^{2} \underline{w}\right] \underline{w}-\left[p^{2} \underline{w}+k(3 p+1)(1-p)\right] \Delta\right\}
$$

If $p \leq \frac{1}{3}$ or $\underline{w} \geq k$, then $k(3 p-1)(1-p)-p^{2} \underline{w} \leq 0$ and thus $C_{\gamma}^{I}$ is concave. If instead $k(3 p-1)(1-p)-p^{2} \underline{w}>0$, then $C_{\gamma}^{\prime \prime}(\Delta)>0$ for $\Delta$ close to $0 ; C_{\gamma}^{I}$ is convex in $[0, \tilde{\Delta}]$ and concave in $[\tilde{\Delta},+\infty)$, where $\tilde{\Delta}$ is such that $\underline{w}\left[k(3 p-1)(1-p)-p^{2} \underline{w}\right]-\left[p^{2} \underline{w}+k(3 p+1)(1-\right.$ $p)] \tilde{\Delta}=0$. In this case we prove below that $C_{\beta \gamma}^{I}(\Delta) \equiv \min \left\{C_{\beta}^{I}(\Delta), C_{\gamma}^{I}(\Delta)\right\}$ is concave. Since $C^{I}(\Delta)=\min \left\{C_{\alpha}^{I}(\Delta), C_{\beta \gamma}^{I}(\Delta), C_{\eta}^{I}(\Delta)\right\}$, we can apply Theorem 5.5 in Rockafellar (1997) to show that $C^{I}$ is concave.

We need to prove that for any $\Delta^{\prime \prime}>\Delta^{\prime} \geq 0$ and any $t \in(0,1)$, the following inequality holds:

$$
C_{\beta \gamma}^{I}\left(\Delta_{t}\right) \geq t C_{\beta \gamma}^{I}\left(\Delta^{\prime}\right)+(1-t) C_{\beta \gamma}^{I}\left(\Delta^{\prime \prime}\right)
$$

where $\Delta_{t}=t \Delta^{\prime}+(1-t) \Delta^{\prime \prime}$. Since $\frac{d C_{\beta}^{I}(0)}{d \Delta}=\frac{d C_{\gamma}^{I}(0)}{d \Delta}=p^{2}+(1-p)^{2} \frac{k}{w}$, the concavity of $C_{\beta}^{I}$ in $[0,+\infty)$ and the convexity of $C_{\gamma}^{I}$ in $[0, \tilde{\Delta}]$ imply $C_{\gamma}^{I}(\Delta)>C_{\beta}^{I}(\Delta)=C_{\beta \gamma}^{I}(\Delta)$ for any $\Delta \in(0, \tilde{\Delta}]$.

Suppose that $\tilde{\Delta} \geq \Delta^{\prime \prime}>\Delta^{\prime} \geq 0$. Then (27) holds because $C_{\beta \gamma}^{I}(\Delta)=C_{\beta}^{I}(\Delta)$ for any $\Delta \in(0, \tilde{\Delta}]$. Now consider the case in which $\Delta^{\prime \prime}>\Delta^{\prime} \geq \tilde{\Delta}$. Since $C_{\beta}^{I}$ and $C_{\gamma}^{I}$ are both concave in $[\tilde{\Delta},+\infty),(27)$ is satisfied by Theorem 5.5 in Rockafellar (1997). 
As a last case, suppose that $0 \leq \Delta^{\prime}<\tilde{\Delta}<\Delta^{\prime \prime}$; then $C_{\beta \gamma}^{I}\left(\Delta^{\prime}\right)=C_{\beta}^{I}\left(\Delta^{\prime}\right)$. If $C_{\beta \gamma}^{I}\left(\Delta_{t}\right)=$ $C_{\beta}^{I}\left(\Delta_{t}\right)$, then $(27)$ holds because $C_{\beta}^{I}\left(\Delta_{t}\right) \geq t C_{\beta}^{I}\left(\Delta^{\prime}\right)+(1-t) C_{\beta}^{I}\left(\Delta^{\prime \prime}\right) \geq t C_{\beta \gamma}^{I}\left(\Delta^{\prime}\right)+(1-$ t) $C_{\beta \gamma}^{I}\left(\Delta^{\prime \prime}\right)$. If instead $C_{\beta \gamma}^{I}\left(\Delta_{t}\right)=C_{\gamma}^{I}\left(\Delta_{t}\right)$, then it must be the case that $\Delta_{t}>\tilde{\Delta}$ and there exists $\bar{t} \in(0,1)$ such that $\Delta_{t}=\bar{t} \tilde{\Delta}+(1-\bar{t}) \Delta^{\prime \prime}$. Since $C_{\gamma}^{I}$ is concave in $[\tilde{\Delta},+\infty)$, we find

$$
\begin{gathered}
C_{\beta \gamma}^{I}\left(\Delta_{t}\right)=C_{\gamma}^{I}\left(\Delta_{t}\right) \geq C_{\gamma}^{I}\left[\bar{t} \tilde{\Delta}+(1-\bar{t}) \Delta^{\prime \prime}\right] \\
\geq \bar{t} C_{\gamma}^{I}(\tilde{\Delta})+(1-\bar{t}) C_{\gamma}^{I}\left(\Delta^{\prime \prime}\right)>\bar{t} C_{\beta}^{I}(\tilde{\Delta})+(1-\bar{t}) C_{\gamma}^{I}\left(\Delta^{\prime \prime}\right)
\end{gathered}
$$

Now let $\hat{t}$ satisfy $\hat{t} \Delta^{\prime}+(1-\hat{t}) \Delta^{\prime \prime}=\tilde{\Delta}$. Then the extreme right hand side of (28) is at least as large as

$$
\begin{gathered}
\bar{t}\left[\hat{t} C_{\beta}^{I}\left(\Delta^{\prime}\right)+(1-\hat{t}) C_{\beta}^{I}\left(\Delta^{\prime \prime}\right)\right]+(1-\bar{t}) C_{\gamma}^{I}\left(\Delta^{\prime \prime}\right) \geq \\
\bar{t} \hat{t} C_{\beta \gamma}^{I}\left(\Delta^{\prime}\right)+\bar{t}(1-\hat{t}) C_{\beta \gamma}^{I}\left(\Delta^{\prime \prime}\right)+(1-\bar{t}) C_{\beta \gamma}^{I}\left(\Delta^{\prime \prime}\right)=\bar{t} \hat{t} C_{\beta \gamma}^{I}\left(\Delta^{\prime}\right)+(1-\bar{t} \hat{t}) C_{\beta \gamma}^{I}\left(\Delta^{\prime \prime}\right)
\end{gathered}
$$

By combining (28) and (29) we see that (27) holds because $\bar{t} \hat{t} \Delta^{\prime}+(1-\bar{t} \hat{t}) \Delta^{\prime \prime}=\Delta_{t}$ and thus $\bar{t} \hat{t}=t$.

\section{Proof of Proposition 5}

(i) The arguments in the text show that the optimal $\Delta$ belongs to $\left\{0, \Delta_{I}^{\max }\right\}$. The payoff when $\Delta=0$ is $2 p Y_{S}-C^{I}(0)-(1-p)\left[2 \psi\left(\frac{C^{I}(0)}{2}\right)-C^{I}(0)\right]$. The payoff when $\Delta=\Delta_{I}^{\max }$ is $2 p Y_{S}-2 p \Delta_{I}^{\max }=2 p Y_{S}-C^{I}\left(\Delta_{I}^{\max }\right)$. Since $C^{I}\left(\Delta_{I}^{\max }\right)<2 \rho+\underline{w}+\left(1-p^{2}\right) k$, A1'(i) implies that the payoff in the best of the two contracts is positive. In particular, by comparing the payoffs in the two contracts we see that the rigid contract is optimal if and only if $C^{I}\left(\Delta_{I}^{\max }\right)-C^{I}(0) \geq(1-p)\left\{2 \psi\left[\frac{1}{2} C^{I}(0)\right]-C^{I}(0)\right\}$.

(ii) The proof of part (ii) is straightforward, hence it is omitted.

\section{References}

Armendáriz de Aghion, B. 1999, "On the Design of a Credit Agreement with Peer Monitoring", Journal of Development Economics, 60:79-104

Armendáriz de Aghion, B. and C. Gollier. 2000, "Peer Group Formation in an Adverse Selection Model", Economic Journal, 110:632-643

Armendáriz de Aghion, B. and J. Morduch. 2005, The Economics of Microfinance, MIT.

Aubert, Cécile, Alain de Janvry and Elisabeth Sadoulet. 2005, "Incentives with Non-Profit Objectives: Microfiancne Agents and the Selection of Very Poor Borrowers", Mimeo, Université Paris Dauphine and University of California at Berkeley. 
Bazoberry, Eduardo. 2001, "We Aren't Selling Vacuum Cleaners: PRODEM's Experiences with Staff Incentives", Microbanking Bulletin, April:11-13.

Besley, T. and S. Coate. 1995, "Group Lending, Repayment, Incentives and Social Collateral", Journal of Development Economics, 44:1-18

Calvo, Guillermo A. and Stanislaw Wellisz, 1978, "Supervision, Loss of Control and the Optimum Size of the Firm", Journal of Political Economy, 86:943-952

Che, Yeon-Koo. 2002, "Joint Liability and Peer Monitoring under Group Lending," Contributions to Theoretical Economics, 2, Article 3.

Conning Jonathan. 1999, "Outreach, sustainability and leverage in monitored and peer-monitored lending", Journal of Development Economics, 60:51-77

David Bornstein, 1996, The Price of a Dream, University of Chicago, Chicago.

Diamond, D. 1984, "Financial Intermediation and Delegated Monitoring," Review of Economic Studies, 51: 393-414.

Fantaye, Dawit Kiros. 2004, "Fighting Corruption and Embezzlement in Third World Countries", Journal of Criminal Law, 68(2): 170-176.

Faure-Grimaud, Antoine, Jean-Jacques Laffont and David Martimort, 2003, "Collusion, Delegation and Supervision with Soft Information", Review of Economic Studies, 70:253-280.

Gale, D. and M. Hellwig, 1985, "Incentive-Compatible Debt Contracts: The OnePeriod Problem," Review of Economic Studies, 52: 647-663.

Ghatak, M. 1999, "Group Lending, Local Information and Peer Selection", Journal of Development Economics, 60:27-50

Ghatak, M. and T. W. Guinnane, 1999, "The Economics of Lending with Joint Liability: Theory and Practice", Journal of Development Economics, 195-228

Jain, Sanjay and Ghazala Mansuri. 2003, "A Little at a time: The Use of Regularly Scheduled Repayments in Microfinance Programs", Journal of Development Economics, 72:253-279

Jeon, Doh-Shin and Domenico Menicucci, 2005, "Optimal Second-degree Price Discrimination and Arbitrage: On the Role of Asymmetric Information among Buyers" Rand Journal of Economics, 36(2): 337-360

Kofman, F. and Lawarrée, J. 1993, "Collusion in Hierarchical Agency" Econometrica, 61:629-656

Laffont, J.-J. 2003, "Collusion and Group Lending with Adverse Selection", Journal of Development Economics, 70: 329-348

Laffont, J.-J and D. Martimort. 2000. "Mechanism Design with Collusion and Corre- 
lation", Econometrica, 68: 309-342.

Laffont, J.-J and D. Martimort. 2002. The Theory of Incentives: the Principal-Agent Model. Princeton University Press.

Laffont, J.-J and T. N'Guessan. 2000, "Group Lending with Adverse Selection", European Economic Review 44:773-784

Laffont, J.-J. and P. Rey, 2003, "Moral Hazard, Collusion and Group Lending", Mimeo, University of Toulouse

Laffont, J.-J. and J. Tirole. 1991, "The Politics of Government Decision Making: A Theory of Regulatory Capture", Quarterly Journal of Economics, 70: 329-348

The Microbanking Bulletin. 2002. "Additional Tables for all MFIs and Financially Self-sufficient MFIs." The Microbanking Bulletin 8 (November): 58-85.

Mknelly Barbara and Michael Kevane, 2000, "Improving Design and Performance of Group Lending: Suggestion from Burkina Faso", World Development 1060:1089-1127.

Jonathan Morduch, 1999, "The Microfinance Promise", Journal of Economic Literature, 37:1569-1614

Rai, A. and T. Sjöström. 2004, "Is Grameen Lending Efficient? Repayment Incentives and Insurance in Village Economies", Review of Economic Studies, 71:217-234.

Rockafellar, R. T., 1997, "Convex Analysis", Princeton University Press.

Stiglitz, J. 1990, "Peer Monitoring and Credit Markets", World Bank Economic Review, 4(3): 351-366

Tirole, Jean, 1986, "Hierarchies and Bureaucracies: On the Role of Collusion in Organizations", Journal of Law, Economics and Organization, 2:181-214

Townsend, R. 1979, "Optimal Contracts and Competitive Markets with Costly State Verification," Journal of Economic Theory 21: 417-425

Varian, H. 1990, "Monitoring Agents With Other Agents", Journal of Institutional and Theoretical Economics 146: 175-176

Williamson, Oliver E., 1967, "Hierarchical Control and Optimum Firm Size" Journal of Political Economy 75:123-38

Yunus, Muhammad, 1998, Banker to the Poor, University Press Limited.

Yunus, Muhammad, 2002, Grameen Bank II Designed to Open New Possibilities http://www.grameen-info.org. 